\title{
Economics
}

The Open-Access, Open-Assessment E-Journal

Vol. 12, 2018-46 | July 23, 2018 | http://dx.doi.org/10.5018/economics-ejournal.ja.2018-46

\section{Income inequality and saving in a class society: the role of ordinal status}

\section{Rein Haagsma}

\begin{abstract}
This paper examines the impact of income growth and income inequality on household saving rates and payoffs in a non-cooperative game where each player's payoff depends on her present and future consumption and her rank in the present consumption distribution. The setting is a pooling equilibrium with three clusters of successive income groups, each cluster having its own present-consumption standard and rank in the present-consumption distribution. In this way the analysis addresses the saving behaviour and welfare of three social classes: the lower, middle and upper class. Explanations are found for the Easterlin paradox and the Kuznets consumption puzzle and it is concluded that rank concerns tend to strengthen the case for more income equality and weaken the standard effect of inequality on aggregate saving.
\end{abstract}

(Published in Special Issue The economics of social status)

JEL C72 D31 D62 E21 Z10 D71

Keywords status; relative consumption; saving; income inequality; income growth

\section{Authors}

Rein Haagsma, Wageningen University and Research Centre, The Netherlands, rein.haagsma@wur.nl

Citation Rein Haagsma (2018). Income inequality and saving in a class society: the role of ordinal status. Economics: The Open-Access, Open-Assessment E-Journal, 12 (2018-46): 1-30. http://dx.doi.org/10.5018/economics-ejournal.ja.2018-46 


\section{Introduction}

In recent decades, a new literature on consumer behaviour has emerged that moves away from the traditional notion that a person's consumption and labour supply are completely independent of what others do. A major line of research builds on the assumption that people care about how their choices compare with those of others in the consumption and income hierarchy. In evaluating their relative position, people tend to be upward-looking and particularly envy those who, in some relevant dimension, are near to them (Frank 1985a: Chapter 2; Elster 1991). One theme in this research programme considers the consequences of social comparison for aggregate saving and another studies the consequences for happiness. For instance, social comparison can explain the observed positive correlation between saving rate and household income, which is hard to reconcile with the life cycle and permanent-income hypotheses (Duesenberry 1949; Frank 1985b Dynan et al. 2004). Social comparison can also explain the well-known Easterlin paradox: the observation of strong growth of real per capita income in Western countries since World War II without any corresponding rise in self-reported happiness (Easterlin 1974; Hirsch 1976; Layard 2005; Clark et al. 2008).

This paper contributes to these themes by analysing the impact of income growth and income inequality on household saving rates and payoffs in a non-cooperative game where each player's payoff depends on her present and future consumption and her rank in the present-consumption distribution. The setting is a specific pooling equilibrium with three clusters of successive income groups, each cluster having its own present-consumption standard and rank in the present-consumption distribution. Within each cluster, their concern with rank induces the members of the lower income groups to consume at the level set by the highest income group, and consequently to neglect saving for future consumption. In this way the analysis aims to address the saving behaviour and welfare of three social classes: the lower, middle and upper class (just three classes for illustrative purposes). In particular, we examine how the social-comparison motive alters the standard analysis of two questions: (1) does across-the-board income growth make everyone better off and also raise the aggregate saving rate? (2) does reducing income inequality by creating a larger middle class favour the poor and increase overall payoff and aggregate saving?

A person's rank in the present-consumption distribution is given by the fraction of people who consume the same as or less than that person. By relating individual choices to rank rather than distance to some average consumption level, the paper follows the seminal article of Frank (1985b) and more recent contributions, including Hopkins and Kornienko (2004, 2009), Becker et al. (2005), Friedman and Ostrov (2008), Ray et al. (2008), Haagsma and van Mouche (2010), and Bilancini and Boncinelli (2014). ${ }^{1}$ The paper particularly builds on the ordinal status game of Haagsma and van Mouche (2010), henceforth HM (2010), which stands out by assuming a finite number of agents instead of

\footnotetext{
1 The ordinal and cardinal measures of status are briefly reviewed by Haagsma and van Mouche (2010) (see also Brown et al. 2008; Clark et al. 2010). Frank et al. (2014) provide an alternative by assuming that a person's consumption positively depends on the consumption of the person whose income ranks just ahead of her income.
} 
an uncountably infinite number. The discretization assumption seems appropriate, since positional concerns typically play a role in small local environments, i.e. where the size of a person's relevant reference group is limited. ${ }^{2}$ An important implication of the above definition of rank in the case of a finite number of consumers is that in their competition for higher position, consumers also have a tendency to conform. Because a first place shared with others yields the same rank as a unique first place, people do not want to fall behind the highest consumption level in their reference group, nor do they want to go ahead of this standard if it is costly to do so. It is this conformist element that creates the possibility of pooling equilibria (see HM, 2010). ${ }^{3}$ The number of consumption standards and thus the social class structure - is an endogenous variable, however, and ultimately depends on the shape of the underlying income distribution. A similar structure of social classes characterizes also the equilibria of the status game studied by Immorlica et al. (2017), where the players are embedded in a network (for other economic explanations of class structure, see e.g. Bernheim 1994; Akerlof 1997; Oxoby 2004).

Once we have linked the standard model of intertemporal consumption and saving to the ordinal status game of HM (2010), the analysis is relatively straightforward and yields the following main results. For each social class, we find that by matching the consumption standard of the highest income group of their class, lower income groups consume too much in the present and save too little for later. This results in lower payoffs as compared with the situation where individual rank is fixed and determined by social class. The saving rate of a lower income group is decreasing in the consumption standard and increasing in income, because higher income relieves the burden of complying with the standard. These results are pretty much in line with the relative income hypothesis of Duesenberry (1949) and the work of Frank (1985a, 1985b), that revived the interest in relative income, and also reflect more recent empirical work on consumption and saving, including Dynan et al. (2004), Alvarez-Cuadrado and El-Attar (2012), and Bertrand and Morse (2016), although none of these studies formalizes class or reference-group structure as such.

Further, we find that economy-wide income growth raises or lowers the aggregate saving rate, depending on whether the highest income groups of each social class see present consumption as a necessity or luxury. For instance, in the case of a luxury good (the example we elaborate on), income growth raises consumption standards more than proportionally, lowering the saving rates of all income groups of a social class. In the case of unitary income elasticity, consumption standards rise at the same pace as income, so that saving

\footnotetext{
2 The continuity assumption becomes critical when it may drive results. For instance, HM (2010) show that if Hopkins and Kornienko's (2004, 2009) specification of the status variable is reformulated for a discrete setting, under general conditions, each (interior) Nash equilibrium has the uncomfortable property that there are as many consumption levels as there are consumers.

3 The term 'pooling equilibrium' is borrowed from the terminology of signalling games, but the analysis assumes complete information. Note that the literature on status seeking focuses on separating equilibria. Just as in a standard economic model with its independent agents, such equilibria imply that people with different characteristics such as income make different choices. In a pooling equilibrium, however, some of them have actually chosen to do the same thing. Perhaps this is indeed how status seeking typically manifests itself: people matching the consumption of those with higher incomes. It certainly conforms with basic sociological notions that propose the uniformity of human behaviour.
} 
rates remain constant. Hence, this case provides a solution to the Kuznets consumption puzzle: the observation that saving rates increase with income in cross-section data but are constant in time series (Kuznets 1942). Our result echoes Duesenberry's proposed solution to the puzzle, which was quickly overshadowed by the life-cycle hypothesis of Modigliani and Brumberg (1954) and the permanent-income hypothesis of Friedman (1957). Note that we obtain this solution under the usual assumption of homothetic preferences (and so unitary income elasticities) of life cycle/permanent-income models.

Although individual payoff is increasing in income, the impact of economy-wide income growth on payoffs is ambiguous. Higher incomes across the board raise the payoffs of those who are in the top income and nearby income groups, but we find that it may hurt consumers at the bottom of a social class. Granted that present consumption is a normal good, the top income groups of the social classes may raise consumption standards to such an extent that bottom income groups, in spite of their higher income, see their payoffs reduced. These results can explain the observation that average happiness scores tend to change more slowly than average income. Thus the analysis offers another illustration of how social comparison can explain the Easterlin paradox (for similar approaches, see Hopkins and Kornienko 2004; Clark et al. 2008).

Establishing more income equality by expanding the middle class particularly alters social ranks and thereby consumption standards. The outflow of people from the lower class to the middle class decreases the social rank of those who stay behind in the lower class, while the outflow of people from the upper class raises the social rank of everyone in the middle class. We prove that this makes those who migrate from the lower class better off as well as those who already were in the middle class. However, people who stay behind in the lower class are worse off. Their social rank has dropped and they have to spend more of their income to conform to the consumption standard of their class, because this has been raised by their peers in response to the lower rank. Evaluating the effect that runs through changes in social rank on overall payoff, we find it can go both ways. That is, it remains an open question whether this effect mitigates or strengthens the standard impact of income redistribution that works through changing class sizes. Nevertheless, we do find that the effect from social comparison strengthens the case for more income equality if the relative income gap between lower and middle class is large. The exposition offers some improvement over the analysis by Hopkins and Kornienko (2004), which can only assess the effects on individual payoffs for given income levels. Whereas their analysis concludes that the poor are worse off under more income equality, we show that this only holds for those who stay behind in the lower class; those who move to a middle-class income group are always better off (for empirical work, see Dynan and Ravina 2007; Oishi et al. 2011).

Since more income equality changes consumption standards, it also changes the average saving rates of the social classes. Because the consumption standard goes up in the lower

\footnotetext{
4 Hopkins and Kornienko (2009) acknowledge this limitation, and offer a complementary approach that allows them to deal with the effects on individual payoffs for a given rank. The current paper implicitly uses both approaches by tracing the effects for any given individual. However, note that we only look at a redistribution of income over social classes, while Hopkins and Kornienko (2004, 2009) study a redistribution over income groups.
} 
class and down in the middle class, the saving rate of the former falls and that of the latter rises. These effects appear in addition to the standard effect of income redistribution on aggregate saving that arises from changing class sizes. The theoretical literature is ambiguous on the sign of the standard effect (for overviews, see Schmidt-Hebbel and Servén 2000; Bovinger and Scheuermeyer 2016). If the marginal propensity to save strictly increases with income, as found by Dynan et al. (2004) for the US, more equality would reduce aggregate saving. Our analysis shows that in this case the social-rank effect of redistributing income tends to mitigate the standard effect. This is in line with a number of recent empirical papers with different modelling of upward-looking comparisons that find that more income equality tends to reduce peer pressures on people's consumption and thus promotes aggregate saving (Alvarez-Cuadrado and El-Attar 2012; Frank et al. 2014; Bertrand and Morse 2016).

The remainder of the paper is organized as follows. Section 2 constructs the basic model and specifies the particular pooling equilibrium with three social classes. Section 3 examines the impact of across-the-board income growth on individual payoffs and aggregate saving. Sections 4-6 study the impact of income inequality on individual payoffs, overall average payoff, and aggregate saving, respectively. Section 7 concludes. A number of appendices support the link between the basic model and the ordinal status game of HM (2010) and also derive sufficient conditions for the existence of the pooling equilibrium.

\section{Basic model}

We start by incorporating social rank in a standard intertemporal model with saving and then link this to the ordinal status game of HM (2010). To increase structure, two additional conditions are introduced, resulting in each Nash equilibrium showing weakly positive sorting, in this case: an increasing relation between income and present consumption. Next, we specify a particular pooling equilibrium with three levels of present consumption and discuss its properties for a simple concrete utility function. This concrete setting also forms the baseline for the remaining sections.

\subsection{Setting the stage}

Consider a standard intertemporal two-period setting with only income in the first period, where individuals have preferences over current and future consumption (we will ignore any bequest motive). Second-period consumption, enjoyed after retirement, is limited by the accumulated saving in the first period plus interest. The quest for a higher social position relates to consumption in the first period. Work done by development psychologists and sociologists suggests that interpersonal comparisons are especially important early in life, when people are busy building a career and setting up a family (see e.g. Frank 1985a: Ch. 8, 1985b; Alvarez-Cuadrado and El-Attar 2012). 
For a given integer $N \geq 2$, let $\mathcal{N}:=\{1, \ldots, N\}$ be the set of consumers. An individual $i \in \mathcal{N}$ chooses a combination of consumption in the two periods, with quantities $c_{(1)}^{i}$ and $c_{(2)}^{i}$, to maximize utility:

$$
U\left(c_{(1)}^{i}, c_{(2)}^{i} ; r^{i}\right)
$$

given a social production function (specified below):

$$
r^{i}=R\left(c_{(1)}^{i} ; \mathbf{c}_{(1)}^{\hat{\imath}}\right)
$$

and subject to a budget constraint:

$$
c_{(1)}^{i}+\frac{1}{1+\rho} c_{(2)}^{i} \leq w^{i} .
$$

Here $r^{i}$ refers to her social rank and $\mathbf{c}_{(1)}^{\hat{\imath}}$ is the vector of first-period consumption levels of all other consumers. The implicit assumption in (2) is that rank really depends on the position in the income distribution, but with no public information on incomes, relative income is inferred from relative consumption (see Frank 1985b; fn.7). The utility function $U: \mathbb{R}_{+}^{2} \times[0,1] \rightarrow \mathbb{R}$ is such that, for each $r^{i} \in[0,1], U\left(\cdot, \cdot ; r^{i}\right)$ is continuous, strictly increasing, and strictly quasi-concave on all budget lines (thus allowing for e.g. a Cobb-Douglas specification). ${ }^{5}$ Moreover, $U$ is strictly increasing in the third variable, the individual's social rank. Further, income $w^{i}>0$ for all $i \in \mathcal{N}$ and interest rate $\rho \geq 0$. Importantly, given our topic, consumers may differ only with respect to income.

We assume that social status is produced in an 'ordinal' way. Hence, the ordering of first-period consumption levels plays a role, rather than their absolute differences. An ordinal measure is close to the sociological literature, where status is connected to rankordered relationships among people, as illustrated by 'social ladder' (see e.g. Ridgeway and Walker 1995). Studies that model positional concerns in terms of ordinal rank typically relate individual actions to the cumulative distribution of other people's actions. ${ }^{6}$ We follow this approach, in particular HM (2010), by assuming that the social rank of individual $i$ depends positively on the fraction of consumers with strictly lower or equal levels of first-period consumption:

$$
R\left(c_{(1)}^{i} ; \mathbf{c}_{(1)}^{\hat{\imath}}\right):=\frac{\#\left\{j \in \mathcal{N} \backslash\{i\} \mid c_{(1)}^{j} \leq c_{(1)}^{i}\right\}}{N-1}
$$

where \# means 'the number of elements of'. Another way of seeing this is that, since leaving more people behind means fewer of them in front, a person's rank depends negatively on

\footnotetext{
5 'Strictly increasing' means that for all $a_{1}, a_{2}, b_{1}, b_{2} \in \mathbb{R}_{+}$, we have $U\left(a_{2}, b_{2} ; r^{i}\right) \geq U\left(a_{1}, b_{1} ; r^{i}\right)$ whenever $a_{2} \geq a_{1}$ and $b_{2} \geq b_{1}$ and the inequality is strict whenever $a_{2}>a_{1}$ and $b_{2}>b_{1}$.

6 Examples are Layard (1980), Frank (1985b), Robson (1992), Hopkins and Kornienko (2004, 2009), Becker et al. (2005), Friedman and Ostrov (2008), Bilancini and Boncinelli (2014). These studies assume an infinite number of agents, whose characteristics are continuously distributed. This assumption is criticised in Haagsma and van Mouche (2010).
} 
the fraction of people with strictly higher consumption levels. The latter interpretation agrees with the hypothesis that people tend to look upward when making comparisons, rather than downward. The importance of upward-looking comparisons already appears from the classic works of Veblen (1899) and Duesenberry (1949), and is also in line with the modern work of Frank (1985a). Some empirical evidence for the hypothesis is provided by Loewenstein et al. (1989), who found through experiments that subjects were more concerned with disadvantageous inequality, where they did worse than their opponents, then with advantageous inequality. Ferrer-i-Carbonell (2005) found for a large German panel data set that self-reported happiness is influenced by higher but not lower-income members of one's reference group. Veblen's and Duesenberry's idea that social comparisons are mostly upwards is also echoed in the literature on (egoistic) relative deprivation (Runciman 1966; see also Stark and Wang 2005) and the welfare-economic notion of envy (Varian 1974; Elster 1991). Two recent papers adopting upward-looking comparisons are Frank et al. (2014) and Immorlica at al. (2017). For a further discussion of (4), see HM (2010).

As usual in this literature, each individual chooses her utility-maximizing combination of consumption, given the choices of all the others. Individuals do so simultaneously and independently, thus the above describes a game in strategic form. Imposing one more restriction on the shape of $U$ :

$$
\max _{\left(c_{(1)}^{i}, c_{(2)}^{i}\right) \in Z^{i}} U(\cdot, \cdot ; 0)>U\left(w^{i}, 0 ; 1\right)
$$

with $Z^{i}:=\left\{\left(c_{(1)}^{i}, c_{(2)}^{i}\right) \in \mathbb{R}_{+}^{2} \mid c_{(1)}^{i}+\frac{1}{1+\rho} c_{(2)}^{i} \leq w^{i}\right\}$, the game boils down to the noncooperative ordinal status game defined and studied by HM (2010). Restriction (5) just implies that spending all income on current consumption can never be a best reply, which avoids trivial corner solutions. The connection with HM (2010) clearly allows us to apply some key results derived in that study. Their game has only a single action variable, but by using the budget constraint $U$ can be expressed in terms of first-period consumption only (see Appendix A).

Finally, a little more structure completes our baseline model by creating, as shown by the proposition below, a positive equilibrium relation between income groups and social classes (ordered with respect to rank). Two conditions are critical, though not far-fetched (see Appendix B for their formal statement). One is that the utility-maximizing quantity of first-period consumption at a given rank differs for consumers with unequal incomes. The other essentially states that if the change in payoffs from an increase in first-period consumption (given the consumption levels of the others) is positive for a specific consumer, then it is also positive for any other consumer whose income is not lower. These conditions are satisfied by assuming from now on that the optimal consumption quantity is an interior solution for all income groups and that the function $U$ also is twice continuously differentiable on the interior of its domain with partial derivatives $-U_{11}, U_{12}, U_{23} \geq 0$ and $U_{22}<0$ (see Appendix B). First-period consumption then is a normal good. ${ }^{7}$ In the next section we will work with a simple concrete utility function that has these properties.

\footnotetext{
7 Though coming close, the second critical condition does not imply that present consumption is a normal good (see Appendix B). Assuming a normal good is consistent with assumption (2) if the underlying idea
} 
Let us denote a Nash equilibrium of first-period consumption levels by $\mathbf{x}=\left(x^{1}, \ldots, x^{N}\right)$. The analysis will build on the following fundamental insights resulting from these two conditions:

Proposition 1 For each Nash equilibrium $\mathbf{x}$ it holds

(1) $w^{i}=w^{j} \Rightarrow x^{i}=x^{j}$;

(2) $w^{i}<w^{j} \Rightarrow x^{i} \leq x^{j}$;

(3) if $\mathbf{x}$ is a separating equilibrium, then $w^{i}<w^{j} \Leftrightarrow x^{i}<x^{j}$.

(A proof is in Appendix B). Suppose, for example, there are 10 income groups, each containing one or more consumers with the same amount of income. The first result of the proposition directly implies that the number of different levels of first-period consumption in a Nash equilibrium are at most 10. Hence, only equilibria with 10 or with fewer than 10 consumption levels can exist. Equilibria with 10 levels, or separating equilibria, show a one-to-one correspondence between consumption level and income group. Equilibria with fewer than 10 levels, or pooling equilibria, show two or more income groups whose members have the same consumption level. The second and third results indicate that, in each Nash equilibrium, the distribution of first-period consumption is positively related to the income distribution. That is, in a separating equilibrium, higher consumption levels correspond to higher income groups. In a pooling equilibrium, at least one quantity of consumption is chosen by two or more successive income groups. ${ }^{8}$ Note that the possibility of a pooling equilibrium increases if income differences become smaller (see HM 2010).

This paper studies a particular pooling equilibrium. To characterize this equilibrium, let us first deal with the following question: if the members of a set of two (or more) successive income groups consume the same amount in a Nash equilibrium, what can we say about their consumption level? So suppose two members $i$ and $j$ with $w^{i}<w^{j}$ and $x^{i}=x^{j}$, and suppose that $w^{j}$ equals the highest income level of this set of successive income groups. Because consumption levels are the same, both have the same social rank: $r^{i}=r^{j}$. This rank is $r^{i}=r^{*}:=R\left(x^{i} ; \mathbf{x}^{\hat{\imath}}\right)$. Now let $\hat{c}_{(1)}(r ; w)$ denote the unique maximizer of the function $U\left(c_{(1)},(1+\rho)\left(w-c_{(1)}\right) ; r\right)$. It is the utility-maximizing quantity of first-period consumption if the individual cannot change her rank $r$. Applying a basic result in HM (2010: Proposition 6), we know that, in any Nash equilibrium, each individual $h$ has a consumption level $x^{h}$ equal to or larger than this quantity at the attained rank $R\left(x^{h} ; \mathbf{x}^{\hat{h}}\right)$, or $x^{h} \geq \hat{c}_{(1)}\left(R\left(x^{h} ; \mathbf{x}^{\hat{h}}\right) ; w^{h}\right)$. Hence, it holds $x^{i} \geq \hat{c}_{(1)}\left(r^{*} ; w^{i}\right)$ and $x^{j} \geq \hat{c}_{(1)}\left(r^{*} ; w^{j}\right)$. Since first-period consumption is a normal good, we have $\hat{c}_{(1)}\left(r^{*} ; w^{i}\right)<\hat{c}_{(1)}\left(r^{*} ; w^{j}\right)$. It follows that the consumption level of the two individuals in the pooling equilibrium is at least $\hat{c}_{(1)}\left(r^{*} ; w^{j}\right)$, that is, at least equal to the utility-maximizing quantity at given rank $r^{*}$ of

is that rank really depends on relative income but incomes are not public knowledge, and thus present consumption - as an observable normal good - may signal income and thus shape the social hierarchy indirectly (see Frank 1985b).

8 The succession property boils down to: if $w^{i}<w^{j}<w^{k}$ and $x^{i}=x^{k}$, then $x^{j}=x^{i}$. We prove this by contradiction, using the second result of the proposition. So suppose $x^{j}<x^{i}$. Then $w^{j}<w^{i}$, which is a contradiction. Suppose $x^{j}>x^{i}$, so also $x^{j}>x^{k}$. Then $w^{j}>w^{k}$, which is also a contradiction. 
members of the highest income group of the cluster. This also illustrates the inefficiency of status seeking. Person $i$ tries to 'catch up with the Joneses' by matching the consumption of person $j$. The former indulges in overconsumption, because she consumes more than if her rank were exogenously fixed at $r^{*}$ (for the Pareto efficiency of separating and pooling equilibria, see HM 2010).

We will study the impact of income growth and redistribution for a pooling equilibrium with three clusters of successive income groups. Each cluster has its own consumption standard, which equals the utility-maximizing quantity of its highest income group. ${ }^{9}$ Since members of the same cluster share the same rank in equilibrium, the clusters are referred to as social classes. Thus a distinction is drawn between the 'lower class', the 'middle class', and the 'upper class'. Many sociologists suggest five social classes (distinguishing also between upper- and lower middle class, and between working class and underclass), but we restrict the divisions to three classes for the sake of clarity. To be sure, the number of social classes is an endogenous variable, however, and ultimately depends on the shape of the underlying income distribution. The formal conditions that guarantee the existence of the particular pooling equilibrium we study implicitly reveal what is assumed about this underlying income distribution.

Specifically, fix three integers $e_{L}, e_{M}$, and $e_{U}$ such that $2 \leq e_{L}, e_{L}+2 \leq e_{M}$, and $e_{M}+2 \leq e_{U}<N$. So $e_{L}<e_{M}<e_{U}$. Let $w_{k}$ denote the fixed income level of income group $k\left(k=1, \ldots, e_{U}\right)$, and assume $w_{1}<\cdots<w_{e_{U}}$. The set of individuals of income group $k$ is $\mathcal{W}_{k}:=\left\{i \in \mathcal{N} \mid w^{i}=w_{k}\right\}$ and their number is $n_{k}:=\# \mathcal{W}_{k} \geq 1$. The lower class is the set of individuals $\mathcal{L}:=\left\{i \in \mathcal{N} \mid w_{1} \leq w^{i} \leq w_{e_{L}}\right\}$ and their number is $N_{L}:=\# \mathcal{L}=\sum_{k=1}^{e_{L}} n_{k}$. Similarly, the middle class is given by $\mathcal{M}:=\left\{i \in \mathcal{N} \mid w_{e_{L}+1} \leq w^{i} \leq w_{e_{M}}\right\}$ with number $N_{M}$, and the upper class by $\mathcal{U}:=\left\{i \in \mathcal{N} \mid w_{e_{M}+1} \leq w^{i} \leq w_{e_{U}}\right\}$ with number $N_{U}$. Of course, $\mathcal{L} \cup \mathcal{M} \cup \mathcal{U}=\mathcal{N}$ and $N_{L}+N_{M}+N_{U}=N$. Hence, for relevance, it is assumed that each of the $e_{U}$ income groups has at least one member and each of the three social classes contains at least two income groups.

The particular pooling equilibrium we consider is a Nash equilibrium $\mathbf{x}$ with $x^{i}=c_{L}$ $(i \in \mathcal{L}), x^{i}=c_{M}(i \in \mathcal{M}), x^{i}=c_{U}(i \in \mathcal{U})$, where

$$
c_{L}<c_{M}<c_{U}
$$

and

$$
c_{L}:=\hat{c}_{(1)}\left(r_{L} ; w_{e_{L}}\right) ; \quad c_{M}:=\hat{c}_{(1)}\left(r_{M} ; w_{e_{M}}\right) ; \quad c_{U}:=\hat{c}_{(1)}\left(r_{U} ; w_{e_{U}}\right)
$$

with (noting (4))

$$
r_{L}:=\frac{N_{L}-1}{N-1} ; \quad r_{M}:=\frac{N_{L}+N_{M}-1}{N-1} ; \quad r_{U}:=\frac{N_{L}+N_{M}+N_{U}-1}{N-1}=1 .
$$

In Appendix $\mathrm{C}$ we derive sufficient conditions for the existence of such a pooling equilibrium. The conditions essentially require that members of the lowest income group of a social

\footnotetext{
9 Given the three clusters of income groups, there generally exists a family of pooling equilibria with three consumption levels (see Appendix C). The selected equilibrium is the Pareto-dominating member of this family (see HM 2010: Proposition 18).
} 
class are not better off by choosing some lower consumption than the standard of their class (conditions (44)-(46)) and members of the highest income group of a social class are not better off by choosing the standard of a higher social class (conditions (47)-(49)). These requirements can be fulfilled by an appropriate shape of the underlying income distribution.

Income growth and redistribution will clearly upset a given pooling equilibrium. Hereafter we consider the implications for a pooling equilibrium where income groups $e_{L}$, $e_{M}$, and $e_{U}$ still set the consumption standard of their social class, though standards may be different than before. Sufficient conditions for the existence of the new pooling equilibrium after income growth or redistribution can be readily constructed using (44)-(49) in Appendix C. However, note that strong income adjustments are likely to alter the class structure of the original pooling equilibrium. For example, a redistribution of income towards the middle class will increase the rank of this social class (see Section 4), and in case of a large increase might induce high-income members of the lower class to adopt the consumption standard of the middle class and enjoy higher status. Thus the number of income groups of a social class might change and even a breakdown into more than three social classes could occur. The exercise below ignores these potential repercussions by considering moderate changes in income that keep the original class structure intact.

\subsection{A concrete baseline}

As baseline, consider a pooling equilibrium with three consumption standards where individual utility is given by

$$
U\left(c_{(1)}^{i}, c_{(2)}^{i} ; r^{i}\right):=\left(c_{(1)}^{i}+\theta r^{i}\right)^{1-\delta} c_{(2)}^{i} \delta
$$

with $0<\delta<1$ and $\theta>0$. Parameter $\theta$ measures sensitivity to rank. The optimal quantity of present consumption if individual $i$ could not change her rank is

$$
c_{(1)}^{i}=\hat{c}_{(1)}\left(r^{i} ; w^{i}\right):=\max \left(0,(1-\delta) w^{i}-\delta \theta r^{i}\right) .
$$

To guarantee an interior solution for consumers of all income groups, it is assumed

$$
w_{1}>\theta \frac{\delta}{1-\delta}
$$

So optimal present consumption is then increasing in income and decreasing in social rank. It is even a luxury good, which accords with its status-signalling function. The negative relation with rank does not necessarily follow from our general assumptions in the previous section, but it is plausible. For example, consider a person's response to an exogenous event that causes the incomes of all other people to rise, and thus to increase their present consumption. Since her own income has not risen while her (exogenous) rank has fallen, the person suffers a decline in utility. The fall in rank raises the marginal payoff from present consumption and lowers that of future consumption, however, so she can reduce 
the decline in utility by saving less and increasing her present consumption. Hence, the negative relation with rank entails a 'keeping up with the Joneses' effect. ${ }^{10}$

The consumption standards of the lower, middle, and upper class follow as

$$
c_{L}=(1-\delta) w_{e_{L}}-\delta \theta r_{L} ; \quad c_{M}=(1-\delta) w_{e_{M}}-\delta \theta r_{M} ; \quad c_{U}=(1-\delta) w_{e_{U}}-\delta \theta
$$

with ranks $r_{L}$ and $r_{M}$ given by (8). The trendsetters of each social class $(i \in$ $\left.\left\{\mathcal{W}_{e_{L}}, \mathcal{W}_{e_{M}}, \mathcal{W}_{e_{U}}\right\}\right)$ consume their optimal amount (by assumption), but their followers consume too much. A follower in the lower class, for example, consumes more than her optimal quantity at the prevailing rank, and her overconsumption is higher, the lower her income:

$$
c_{L}-\hat{c}_{(1)}\left(r_{L} ; w^{i}\right)=(1-\delta)\left(w_{e_{L}}-w^{i}\right)>0 \quad\left(i \in \mathcal{L} \backslash \mathcal{W}_{e_{L}}\right) .
$$

Figure 1(A) illustrates the implied gap in payoffs due to overconsumption by drawing a comparison with the situation where an individual's rank would be fixed and determined by her social class (indicated by the upper solid lines). ${ }^{11}$ Note that individual payoffs are increasing in income. In particular, a follower has a higher payoff than any trendsetter with a lower income since the former is able to match the consumption level of the latter and at the same time save more (in Appendix D we prove that payoff increases by social class).

Overconsumption is accompanied by undersaving. For example, the saving rate $s^{i}$ of a follower in the lower class is

$$
s^{i}:=1-\frac{c_{(1)}^{i}}{w^{i}}=1-\frac{c_{L}}{w^{i}}<1-\frac{\hat{c}_{(1)}\left(r_{L} ; w^{i}\right)}{w^{i}} \quad\left(i \in \mathcal{L} \backslash \mathcal{W}_{e_{L}}\right) .
$$

Hence, the saving rate of a follower is decreasing in the consumption standard and it is increasing in income because higher income relieves the burden of complying with the standard. However, the saving rate of a trendsetter (the right-hand side of (14) with $i \in \mathcal{W}_{e_{L}}$ ), is decreasing in income if present consumption is a luxury good, which is the case here. ${ }^{12}$ The relationship between income and saving rate for the three social classes typically describes a saw-like curve, as sketched in Figure 1(B). Note that a higher sensitivity to rank $(\theta)$ raises saving rates of both followers and trendsetters, because this lowers the marginal payoff from present consumption and thus also from consumption standards.

Hereafter, the impact of income growth and redistribution is studied for individual payoffs and the aggregate saving rate, denoted by $\bar{s}$. The latter is a weighted sum of the average saving rates of the three social classes:

$$
\bar{s}:=\frac{N_{L}}{N} \bar{s}_{L}+\frac{N_{M}}{N} \bar{s}_{M}+\frac{N_{U}}{N} \bar{s}_{U}
$$

\footnotetext{
${ }^{10}$ This is in line with Clarke and Oswald's (1998) observation that individuals with 'comparison-concave utility' follow others' actions.

${ }^{11}$ For example, for a member of the lower class, the gap is given by the difference between $U\left(\hat{c}_{(1)}\left(r_{L} ; w^{i}\right),(1+\right.$ $\left.\rho)\left(w^{i}-\hat{c}_{(1)}\left(r_{L} ; w^{i}\right)\right) ; r_{L}\right)$ and $U\left(c_{L},(1+\rho)\left(w^{i}-c_{L}\right) ; r_{L}\right)$.

12 A trendsetter of the lower class has $s^{i}=\delta\left(1+\theta r_{L} / w_{e_{L}}\right)$.
} 
where

$$
\bar{s}_{L}:=\frac{1}{N_{L}} \sum_{i \in \mathcal{L}} s^{i}=1-\frac{c_{L}}{N_{L}} \sum_{k=1}^{e_{L}} \frac{n_{k}}{w_{k}} ; \quad \bar{s}_{M}=1-\frac{c_{M}}{N_{M}} \sum_{k=e_{L}+1}^{e_{M}} \frac{n_{k}}{w_{k}} ; \quad \bar{s}_{U}=1-\frac{c_{U}}{N_{U}} \sum_{k=e_{M}+1}^{e_{U}} \frac{n_{k}}{w_{k}} .
$$

\section{Is income growth for everyone beneficial for everyone?}

Suppose everyone's income rises with the same percentage. Then clearly everyone would be better off if consumption standards $c_{L}, c_{M}$, and $c_{U}$ stayed put. However, as indicated by (12), the trendsetters of the social classes can gain even more by increasing the consumption standards. While the trendsetters, then, are always better off, this is not immediately clear for the followers, typically the majority of the consumers.

Therefore, suppose the income of each consumer $i(i \in \mathcal{N})$ rises from $w^{i}$ to $w^{i \prime}$ according to

$$
w^{i \prime}=(1+g) w^{i} \text { with } g \geq 0
$$

but $g$ not too large to preserve our type of pooling equilibrium where income groups $e_{L}$, $e_{M}$, and $e_{U}$ set the consumption standards. Again taking a member of the lower class, her payoff becomes

$$
U\left(c_{L}^{\prime},(1+\rho)\left((1+g) w^{i}-c_{L}^{\prime}\right) ; r_{L}\right) \text { with } c_{L}^{\prime}:=(1-\delta)(1+g) w_{e_{L}}-\delta \theta r_{L} .
$$

Sufficient for being strictly better off is that the increase in income $\left(g w^{i}\right)$ covers the extra expenditure due to the higher standard $\left(c_{L}^{\prime}-c_{L}\right)$, so that while first-period consumption increases her saving does not fall. This comes down to $w^{i} \geq(1-\delta) w_{e_{L}}$, which holds for consumers with incomes close to those of trendsetters but not necessarily for poor consumers of this class.

By differentiating (18) with respect to $g$ using (9) and evaluating at $g=0$, we find a necessary and sufficient condition for being strictly better off:

$$
w^{i}>\frac{(1-\delta) w_{e_{L}}}{w_{e_{L}}+\delta \theta r_{L}} \cdot w_{e_{L}} \quad(i \in \mathcal{L})
$$

(note that the ratio is less than 1). The condition may not hold for consumers at the bottom of the lower class. For this category, adhering to the increased consumption standard may be accompanied by such a large decline in saving, and thus also future consumption, that, in spite of their higher income, their payoff will fall.

Let us see how concerns for rank can explain the Easterlin paradox. To do this, we examine the relationship between the growth rate of income and the growth rate of individual payoff (as an indicator of happiness, see Section 1). Just for now it is convenient 
to measure time as a continuous variable and consider a restricted time path that preserves the particular type of pooling equilibrium. Let $v_{L}^{i}$ denote the payoff growth rate of individual $i$ in the lower class. ${ }^{13}$ Then the latter is simply proportional to the income growth rate $g$ :

$$
v_{L}^{i}=g\left[(1-\delta) \frac{w_{e_{L}}}{w_{e_{L}}+\theta r_{L}}+\delta \frac{w^{i}-(1-\delta) w_{e_{L}}}{w^{i}-(1-\delta) w_{e_{L}}+\delta \theta r_{L}}\right] \quad(i \in \mathcal{L})
$$

(using (9)). Consider first the members of the highest income group, i.e. with $w^{i}=w_{e_{L}}$. Their payoff growth rate follows as $v_{L}^{i}=g\left[\frac{w_{e_{L}}}{w_{e_{L}}+\theta r_{L}}\right]\left(i \in \mathcal{W}_{e_{L}}\right)$, which is less than the growth rate of their income. Further, because the second ratio of (20) is smaller than the first ratio if $w^{i}<w_{e_{L}}$, the payoff growth rate of lower income groups is lower than that of the highest income group. Indeed, it is easily verified that the lower the income, the lower the growth rate of payoff. Hence, the lowest payoff growth rate occurs in the lowest income group. Payoff growth rates at the bottom of the social class are even zero or negative if condition (19) fails to hold. Of course, similar results are obtained for the middle and upper class. Taken together, then, this implies that the change in the average payoff of a social class can seriously lag behind universal income growth. The analysis thus supports the empirical observation, first made by Easterlin (1974), that average happiness scores seem to move more slowly than average income.

Though high-income groups of a social class are able to save more when income rises, saving rates fall for everyone. The saving rate of a member of the lower class becomes

$$
s^{i \prime}:=1-\frac{c_{L}{ }^{\prime}}{w^{i \prime}}<1-\frac{c_{L}}{w^{i}}=s^{i} \quad(i \in \mathcal{L}, g>0)
$$

(using (12), (17) and (18)). Hence, economy-wide income growth induces such higher consumption standards that it decreases the aggregate saving rate. Note that this result critically hinges on the property that trendsetters consider present consumption to be a luxury good. Ignoring for the moment our specification of preferences (9), it is easily verified that the aggregate saving rate increases or decreases, depending on whether the trendsetting income groups see present consumption as a necessity or a luxury, and stays constant in the case of unitary income elasticity. The latter case provides a solution to the Kuznets consumption puzzle (see Section 1). Specifically, we already found that saving rates are increasing in income for followers (arguably the majority of consumers, see (14)) and now we know that, under unitary income elasticity, saving rates stay constant if income changes across the board.

\section{Does more income equality favour the poor?}

Suppose a more equal income distribution is contemplated that expands the size of the middle class by reducing the numbers of people in the lower and upper class. While

\footnotetext{
${ }^{13}$ Let $t$ denote time and write $w^{i}(t)$ and $w_{e_{L}}(t)$. Then $g$ is the growth rate of $w^{i}(t)$ and $v_{L}^{i}$ is defined as the growth rate of $U\left(c_{L}(t),(1+\rho)\left(w^{i}(t)-c_{L}(t)\right) ; r_{L}\right)$ with $c_{L}(t):=(1-\delta) w_{e_{L}}(t)-\theta \delta r_{L}(i \in \mathcal{L})$.
} 
traditional analysis points at the benefits of such a policy for people in the lower income brackets, the picture is more diffuse now, because redistribution of income may alter social ranks and consumption standards. Specifically, the outflow of people to the middle class lowers the social rank of those who stay behind in the lower class, thereby inducing a higher consumption standard. In contrast, the inflow of people from the upper class raises the social rank of everyone in the middle class, which causes a fall in the consumption standard. Whether an egalitarian income policy has the intended effects, therefore, remains to be seen.

Consider the following redistribution scheme. Suppose a random draw of members of the lower class and a random draw of members of the upper class are randomly allocated to the income groups of the middle class, keeping aggregate income constant. Fix the proportion of the lower social class that flows out, denoted by $\alpha(0 \leq \alpha<1)$. Then the redistribution is such that the size of an income group becomes an integer $n_{k}^{\prime}$ with

$$
n_{k}^{\prime}:=\left\{\begin{array}{lll}
(1-\alpha) n_{k} & \text { if } \quad k=1, \ldots, e_{L} \\
(1+\gamma) n_{k} & \text { if } \quad k=e_{L+1}, \ldots, e_{M} \\
(1-\beta) n_{k} & \text { if } \quad k=e_{M+1}, \ldots, e_{U}
\end{array}\right.
$$

where $\beta$ is the proportion of the upper class that flows out and $\gamma$ the growth rate of the middle class. The value of $\beta$ follows from the condition that the total income gain of those who leave the lower class must be equal to the total income loss of those who leave the upper class. If $\bar{w}_{L}$ is the average income of the lower class $\left(\bar{w}_{L}:=\frac{1}{N_{L}} \sum_{i \in \mathcal{L}} w^{i}\right)$ and $\bar{w}_{M}$ and $\bar{w}_{U}$ the average incomes of the middle and upper class, $\beta$ follows from

$$
\left(\bar{w}_{M}-\bar{w}_{L}\right) \alpha N_{L}=\left(\bar{w}_{U}-\bar{w}_{M}\right) \beta N_{U}
$$

(it is assumed that $\alpha$ is small enough to yield $\beta<1$ ). Finally, $\gamma$ is implied by

$$
\gamma N_{M}=\alpha N_{L}+\beta N_{U}
$$

Note that the degree of income redistribution is entirely determined by the value of $\alpha$. As before, we consider moderate changes in $\alpha$ that induce a pooling equilibrium where income groups $e_{L}, e_{M}$, and $e_{U}$ still set the consumption standards.

Using primes for ex post variables, the scheme changes the ranks of the social classes as follows:

$$
\begin{aligned}
& r_{L}^{\prime}:=\frac{N_{L}^{\prime}-1}{N-1}=\frac{(1-\alpha) N_{L}-1}{N-1}=r_{L}-\alpha \frac{N_{L}}{N-1}<r_{L} \\
& r_{M}^{\prime}:=\frac{N_{L}^{\prime}+N_{M}^{\prime}-1}{N-1}=\frac{(1-\alpha) N_{L}+(1+\gamma) N_{M}-1}{N-1}=r_{M}+\beta \frac{N_{U}}{N-1}>r_{M} \\
& r_{U}^{\prime}:=\frac{N_{L}^{\prime}+N_{M}^{\prime}+N_{U}^{\prime}-1}{N-1}=1=r_{U} .
\end{aligned}
$$


So, while nothing happens with the social rank of the upper class, the rank of the lower class falls by $\alpha \frac{N_{L}}{N-1}$, whereas the rank of the middle class rises by $\beta \frac{N_{U}}{N-1}$. For the new consumption standards, we find accordingly

$$
c_{L}^{\prime}:=\hat{c}_{(1)}\left(r_{L}^{\prime} ; w_{e_{L}}\right)>c_{L} ; \quad c_{M}^{\prime}:=\hat{c}_{(1)}\left(r_{M}^{\prime} ; w_{e_{M}}\right)<c_{M} ; \quad c_{U}^{\prime}:=\hat{c}_{(1)}\left(r_{U}^{\prime} ; w_{e_{U}}\right)=c_{U} .
$$

These adjustments follow from the property that standards are decreasing in rank, which is implied by our specification of preferences (9) and consistent with following behaviour (as in 'keeping up with the Joneses').

Let us now determine the welfare effects of the redistribution scheme. To shorten notation, define for $i \in \mathcal{W}_{k}\left(k=1, \ldots, e_{U}\right)$

$$
V^{k}\left(c_{(1)}^{i}, r^{i}\right):=U\left(c_{(1)}^{i},(1+\rho)\left(w_{k}-c_{(1)}^{i}\right) ; r^{i}\right)
$$

and note that $V^{k}\left(\cdot, r^{i}\right)$ is downward-sloping if $c^{i}>\hat{c}_{(1)}\left(r^{i} ; w_{k}\right)$. We have to consider the change in payoff for five groups of individuals:

- Those who stay in the lower class are worse off, due to both the lower rank and the higher standard.

Formally, we have $V^{k}\left(c_{L}{ }^{\prime}, r_{L}{ }^{\prime}\right)<V^{k}\left(c_{L}{ }^{\prime}, r_{L}\right)\left(k=1, \ldots, e_{L}\right)$. Because $c_{L}<c_{L}{ }^{\prime}$, it holds $\hat{c}_{(1)}\left(r_{L} ; w_{k}\right) \leq c_{L}<c_{L}{ }^{\prime}$. Therefore, $V^{k}\left(c_{L}{ }^{\prime}, r_{L}\right)<V^{k}\left(c_{L}, r_{L}\right)$.

- Those who stay in the middle class are better off, because of both the higher rank and the lower standard.

Formally, we have $V^{k}\left(c_{M}{ }^{\prime}, r_{M}{ }^{\prime}\right)>V^{k}\left(c_{M}{ }^{\prime}, r_{M}\right)\left(k=e_{L+1}, \ldots, e_{M}\right)$. Because $c_{M}>$ $c_{M}^{\prime}$, it holds $\hat{c}_{(1)}\left(r_{M}^{\prime} ; w_{k}\right) \leq c_{M}^{\prime}<c_{M}$. Therefore, $V^{k}\left(c_{M}{ }^{\prime}, r_{M}\right)>V^{k}\left(c_{M}, r_{M}\right)$.

- Those who stay in the upper class are unaffected, since both rank and standard remain the same.

- Those who leave the lower class are better off for two reasons: as shown above, middle-class consumers are better off than before, and payoff always increases by social class.

Formally, above we derived $V^{k}\left(c_{M^{\prime}}, r_{M^{\prime}}\right)>V^{k}\left(c_{M}, r_{M}\right)\left(k=e_{L+1}, \ldots, e_{M}\right)$. Proposition 7 in Appendix D implies $V^{k}\left(c_{M}, r_{M}\right)>V^{l}\left(c_{L}, r_{L}\right)\left(l=1, \ldots, e_{L}\right)$.

- Those who leave the upper class are worse off for two reasons: payoff is always lower in a lower social class and upper-class consumers are unaffected.

Formally, Proposition 7 in Appendix D implies $V^{k}\left(c_{M}^{\prime}, r_{M}^{\prime}\right)<V^{l}\left(c_{U}^{\prime}, r_{U}^{\prime}\right)(k=$ $\left.e_{L+1}, \ldots, e_{M} ; l=e_{M+1}, \ldots, e_{U}\right)$. Above we noted $V^{l}\left(c_{U}^{\prime}, r_{U}^{\prime}\right)=V^{l}\left(c_{U}, r_{U}\right)$.

In sum, returning to the question of whether a more equal income distribution favours the poor, the answer is yes, and no. The policy results in both lower-class consumers receiving a higher income and middle-class consumers being better off. However, lower-class consumers who do not receive a higher income are worse off. Their rank in the social 
hierarchy drops and they have to spend more of their income to conform to the consumption standard of their class, because this has been raised by their peers in response to the lower rank.

\section{Does more income equality increase happiness?}

Let us now take a utilitarian approach and use the results in the previous section to explore whether a more equal income distribution increases overall average payoff (as an indicator of 'mean happiness'). Particularly, we are interested in how the social-comparison component alters the standard effect of income equality on average payoff.

Therefore, let $\bar{V}$ denote overall average payoff and define

$$
\bar{V}:=\frac{N_{L}}{N} \bar{V}_{L}+\frac{N_{M}}{N} \bar{V}_{M}+\frac{N_{U}}{N} \bar{V}_{U}
$$

where

$$
\bar{V}_{L}:=\frac{1}{N_{L}} \sum_{i \in \mathcal{L}} U\left(c_{(1)}^{i},(1+\rho)\left(w^{i}-c_{(1)}^{i}\right) ; r^{i}\right)=\frac{1}{N_{L}} \sum_{k=1}^{e_{L}} n_{k} V^{k}\left(c_{L}, r_{L}\right)
$$

is the average payoff of the lower class, and similar definitions apply to those of the middle and upper class, $\bar{V}_{M}$ and $\bar{V}_{U}$. Overall average payoff after income redistribution $\left(\bar{V}^{\prime}\right)$ can be written as

$$
\bar{V}^{\prime}=\frac{(1-\alpha) N_{L}}{N} \bar{V}_{L}^{\prime}+\frac{(1+\gamma) N_{M}}{N} \bar{V}_{M}^{\prime}+\frac{(1-\beta) N_{U}}{N} \bar{V}_{U}^{\prime}
$$

where

$$
\begin{aligned}
& \bar{V}_{L}^{\prime}=\frac{1}{N_{L}^{\prime}} \sum_{k=1}^{e_{L}} n_{k}^{\prime} V^{k}\left(c_{L}^{\prime}, r_{L}^{\prime}\right)=\frac{1}{N_{L}} \sum_{k=1}^{e_{L}} n_{k} V^{k}\left(c_{L}^{\prime}, r_{L}^{\prime}\right) ; \\
& \bar{V}_{M}^{\prime}=\frac{1}{N_{M}} \sum_{k=e_{L}+1}^{e_{M}} n_{k} V^{k}\left(c_{M}^{\prime}, r_{M}^{\prime}\right) ; \bar{V}_{U}^{\prime}=\frac{1}{N_{U}} \sum_{k=e_{M}+1}^{e_{U}} n_{k} V^{k}\left(c_{U}^{\prime}, r_{U}^{\prime}\right) .
\end{aligned}
$$

Now recall that the payoffs of individuals who stay in the upper class are unaffected, so $\bar{V}_{U}^{\prime}=\bar{V}_{U}$.

Then, using (24), the induced change in overall average payoff can be split up into these two terms:

$$
\bar{V}^{\prime}-\bar{V}=\frac{1}{N}\left[\alpha N_{L}\left(\bar{V}_{M}-\bar{V}_{L}\right)-\beta N_{U}\left(\bar{V}_{U}-\bar{V}_{M}\right)\right]+\frac{1}{N}\left[(1-\alpha) N_{L}\left(\bar{V}_{L}^{\prime}-\bar{V}_{L}\right)+(1+\gamma) N_{M}\left(\bar{V}_{M}^{\prime}-\bar{V}_{M}\right)\right] .
$$

The first term is the standard effect of redistributing income. It compares the gain of those who flow from the lower class into the middle class with the loss of those who arrive from 
the upper class. The second term arises because income redistribution changes the ranks of the social classes. The two effects are examined further below.

Regarding the standard effect, let us eliminate $\beta$ by defining

$$
\Delta:=\frac{\bar{w}_{M}-\bar{w}_{L}}{\bar{w}_{U}-\bar{w}_{M}} .
$$

Note that $\Delta$ is a strictly positive parameter. It measures the relative income gap between lower and middle class, as compared with the income gap between middle and upper class. Then the first term of (34) can be written as

$$
\frac{\alpha N_{L}}{N}\left[\left(\bar{V}_{M}-\bar{V}_{L}\right)-\Delta\left(\bar{V}_{U}-\bar{V}_{M}\right)\right]
$$

(using (23)). For example, if $\Delta=1$ (income gaps between social classes are the same), the standard effect is positive if average payoff increases by social class at a decreasing rate. This reflects the Benthamite proposal for reducing income inequality.

The second term sums two expressions (see (34)). The first one is negative since $\bar{V}_{L}^{\prime}<\bar{V}_{L}$, and refers to the loss in payoff for those who stay behind in the lower class. The second expression is positive since $\bar{V}_{M}^{\prime}>\bar{V}_{M}$, and measures the gain for those who already were in the middle class $\left(N_{M}\right)$ and what could be seen as a bonus for the new arrivals $\left(\gamma N_{M}\right)$. Those who arrived from the lower class receive more than the initial payoff of the middle class $\left(\bar{V}_{M}\right)$ and those who arrived from the upper class suffer less than in the case of the initial payoff of the middle class. Without further assumptions the second term cannot be signed. However, noting that $\gamma=\alpha(1+\Delta) N_{L} / N_{M}$ (using (23) and (24)), we can see that the larger the relative income gap between lower and middle class $(\Delta),{ }^{14}$ the more likely the second term is positive. Hence, the effect due to social comparison strengthens the case for income redistribution by increasing overall average payoff provided that this relative income gap is large enough.

\section{Does more income equality increase aggregate saving?}

In the neoclassical case with homothetic preferences over present and future consumption, saving rates do not depend on income. Redistributing income then has no impact on the aggregate saving rate. With more general preferences where saving rates do depend on income, redistributing income typically alters the aggregate saving rate through its impact on the weights given by the relative sizes of the income groups, or, under the above redistribution scheme, the relative sizes of the social classes. In the case of social comparison, however, there is an additional effect. Since the scheme changes social ranks and thus consumption standards, it also affects the average saving rates of the social classes.

The aggregate saving rate after income redistribution $\left(\bar{s}^{\prime}\right)$ can be written as

$$
\bar{s}^{\prime}=\frac{(1-\alpha) N_{L}}{N} \bar{s}_{L}^{\prime}+\frac{(1+\gamma) N_{M}}{N} \bar{s}_{M}^{\prime}+\frac{(1-\beta) N_{U}}{N} \bar{s}_{U}^{\prime}
$$

${ }^{14}$ Note that $\bar{w}_{U}$ is a free variable here. 
where

$$
\begin{aligned}
& \bar{s}_{L}^{\prime}=1-\frac{c_{L}^{\prime}}{N_{L}^{\prime}} \sum_{k=1}^{e_{L}} \frac{n_{k}^{\prime}}{w_{k}}=1-\frac{c_{L}^{\prime}}{N_{L}} \sum_{k=1}^{e_{L}} \frac{n_{k}}{w_{k}} ; \\
& \bar{s}_{M}^{\prime}=1-\frac{c_{M}^{\prime}}{N_{M}} \sum_{k=e_{L}+1}^{e_{M}} \frac{n_{k}}{w_{k}} ; \quad \bar{s}_{U}^{\prime}=1-\frac{c_{U}^{\prime}}{N_{U}} \sum_{k=e_{M}+1}^{e_{U}} \frac{n_{k}}{w_{k}}
\end{aligned}
$$

(see Section 4 and (15) and (16)). Now note that, since the consumption standard of the upper class is unaffected by redistribution, the saving rate of this class stays the same: $\bar{s}_{U}^{\prime}=\bar{s}_{U}$.

Then the induced change is given by the sum of two terms:

$$
\bar{s}^{\prime}-\bar{s}=\frac{1}{N}\left[\alpha N_{L}\left(\bar{s}_{M}-\bar{s}_{L}\right)-\beta N_{U}\left(\bar{s}_{U}-\bar{s}_{M}\right)\right]+\frac{1}{N}\left[(1-\alpha) N_{L}\left(\bar{s}_{L}^{\prime}-\bar{s}_{L}\right)+(1+\gamma) N_{M}\left(\bar{s}_{M}^{\prime}-\bar{s}_{M}\right)\right] .
$$

Just as in the previous section, the first term is a standard effect that occurs through the change in the relative sizes of the social classes. Redistribution expands the middle class by inflows of $\alpha N_{L}$ consumers from the lower class and $\beta N_{U}$ consumers from the upper class. The second term is the additional effect due to social comparison, which causes changes in the saving rates of the lower and middle class.

Using (23) and (35), the first term of (39) can be written as

$$
\frac{\alpha N_{L}}{N}\left[\left(\bar{s}_{M}-\bar{s}_{L}\right)-\Delta\left(\bar{s}_{U}-\bar{s}_{M}\right)\right]
$$

This shows that the direction of the standard effect is independent of the degree of income redistribution $(\alpha)$. If $\Delta=1$ (income gaps between social classes are the same), the standard effect is negative if the average saving rate rises by social class at an increasing rate: more income equality then reduces aggregate saving. The opposite holds if the average saving rate rises at a decreasing rate.

As for the additional effect, a little calculation shows that

$$
\begin{aligned}
& \bar{s}_{L}^{\prime}-\bar{s}_{L}=\frac{c^{L}-c^{L \prime}}{N_{L}} \sum_{k=1}^{e_{L}} \frac{n_{k}}{w_{k}}=\frac{\delta \theta\left(r_{L}^{\prime}-r_{L}\right)}{N_{L}} \sum_{k=1}^{e_{L}} \frac{n_{k}}{w_{k}}<0 \\
& \bar{s}_{M}^{\prime}-\bar{s}_{M}=\frac{c^{M}-c^{M \prime}}{N_{M}} \sum_{k=e_{L}+1}^{e_{M}} \frac{n_{k}}{w_{k}}=\frac{\delta \theta\left(r_{M}^{\prime}-r_{M}\right)}{N_{M}} \sum_{k=e_{L}+1}^{e_{M}} \frac{n_{k}}{w_{k}}>0
\end{aligned}
$$

using (12), (25) and (26). Hence, because the consumption standard increases in the lower class and decreases in the middle class, the saving rate of the former falls and that of the latter rises. This already suggests that the direction of the additional effect is ambiguous. Using (22)-(25), the second term of (39) can be expressed as

$$
\frac{\alpha N_{L}}{N} \frac{\delta \theta}{N-1}\left[(1+\gamma) \Delta \sum_{k=e_{L}+1}^{e_{M}} \frac{n_{k}}{w_{k}}-(1-\alpha) \sum_{k=1}^{e_{L}} \frac{n_{k}}{w_{k}}\right] \text { with } \gamma=\alpha(1+\Delta) \frac{N_{L}}{N_{M}}
$$


The bracketed term cannot be signed a priori, but it is seen that a positive outcome becomes more likely as the degree of redistribution $\alpha$ increases. Also, if the relative income gap between lower and middle class $(\Delta)$ is small, redistribution tends to have a negative additional effect. If the relative income gap $(\Delta)$ is large, it is just the opposite: redistribution tends to have a positive additional effect.

Let us draw a conclusion for the plausible case where saving rates rise by social class, so $\bar{s}_{L}<\bar{s}_{M}<\bar{s}_{U}$. If the relative income gap between lower and middle class $(\Delta)$ is small, redistribution tends to have a positive standard effect (it increases aggregate saving) and a negative additional effect. If the relative income gap $(\Delta)$ is large, redistribution tends to have a negative standard effect (it decreases aggregate saving) and a positive additional effect. Our conclusion then is that income redistribution in the case of upward-looking comparisons is likely to mitigate the standard effect of income redistribution on aggregate saving.

\section{Conclusion}

Above we analysed how social-rank concerns alter the usual impact of income growth and redistribution on individual payoffs and saving rates. After linking the standard model of intertemporal consumption and saving to the ordinal status game of Haagsma and van Mouche (2010), the analysis yielded explanations for the Easterlin paradox and the Kuznets consumption puzzle. Moreover, rank concerns were found to strengthen the case for more income equality if the income gap between lower and middle class is relatively large and rank concerns tended to weaken the standard effect of income inequality on aggregate saving.

Assuming a finite number of consumers differing only in income, an individual's social rank was defined as the fraction of consumers who spend the same as or less than her on present consumption. The resulting interdependency among consumers can give rise to two types of Nash equilibria: separating equilibria, where each income group has its own consumption standard, and pooling equilibria, where at least one consumption standard is shared by two or more income groups. Whereas the literature focuses on separating equilibria with a continuum of agents, the paper shows that it is the possibility of pooling equilibria that offers another step towards a more realistic account of the phenomenon of status seeking. Perhaps this is indeed the typical manifestation of status seeking: people not only raising their spending but actually matching the consumption expenditure of those in slightly higher income groups. In any case, it accords with basic sociological notions that social interdependence promotes uniform behaviour. The possibility of pooling equilibria can also illustrate the phenomenon of class structure. While we distinguished three social classes, the number of classes is an endogenous variable ultimately determined by the shape of the underlying income distribution.

Acknowledgment The author wishes to thank two anonymous referees, Pierre van Mouche, and Hans-Peter Weikard for helpful comments and suggestions. 


\section{APPENDIX $^{15}$}

\section{Appendix A}

We show that the game is an 'ordinal status game' as defined and studied by HM (2010). Since, for each $r^{i} \in[0,1], U\left(\cdot, \cdot ; r^{i}\right)$ is strictly increasing, the budget constraint will hold with strict equality at any maximizer and equilibrium, so we can substitute for $c_{(2)}^{i}$ in $U$ and write

$$
U\left(c_{(1)}^{i},(1+\rho)\left(w^{i}-c_{(1)}^{i}\right) ; r^{i}\right) .
$$

With $X^{i}:=\left[0, L^{i}\right]:=\left[0, w^{i}\right]$ the domain of the action variable $x^{i}$ and $Q:=\left\{q_{1}, \ldots, q_{N}\right\}$ with $q_{k}:=\frac{k-1}{N-1}(k \in \mathcal{N})$ the domain of the rank variable $r^{i}$ (note that $Q \subseteq[0,1]$ ), we define the function $u^{i}: X^{i} \times Q \rightarrow \mathbb{R}$ by

$$
u^{i}\left(x^{i}, r^{i}\right):=U\left(x^{i},(1+\rho)\left(w^{i}-x^{i}\right) ; r^{i}\right) .
$$

Then using (4) we arrive at the payoff function $v^{i}: X^{1} \times \cdots \times X^{N} \rightarrow \mathbb{R}$ as defined by HM (2010):

$$
v^{i}(\mathbf{x})=u^{i}\left(x^{i}, \frac{\#\left\{j \in \mathcal{N} \backslash\{i\} \mid x^{j} \leq x^{i}\right\}}{N-1}\right) .
$$

The assumed shape of $U$ ensures that function $u^{i}$ is continuous in the first variable, strictly quasi-concave in the first variable, and strictly increasing in the second variable. Restriction (5) ensures that $u^{i}$ also satisfies the so-called relevance condition mentioned by HM (2010). Hence, the game indeed is an ordinal status game.

\section{Appendix B}

Formally, the two conditions that complete our baseline model are as follows. Let $\hat{c}_{(1)}\left(r ; w^{i}\right)$ denote the unique maximizer of the function $u^{i}\left(c_{(1)}, r\right):=U\left(c_{(1)},(1+\rho)\left(w^{i}-c_{(1)}\right) ; r\right)$.

Condition 1 For each $r \in[0,1]$ and $i, j \in \mathcal{N}: w^{i} \neq w^{j} \Rightarrow \hat{c}_{(1)}\left(r ; w^{i}\right) \neq \hat{c}_{(1)}\left(r ; w^{j}\right) . \diamond$

Condition 2 For all $i, j \in \mathcal{N}$ with $w^{i} \leq w^{j}, r, r^{\prime} \in[0,1]$ with $r^{\prime} \geq r$, and $c, c^{\prime} \in\left[0, w^{i}\right]$ with $c^{\prime}>c$ :

$$
u^{i}\left(c^{\prime}, r^{\prime}\right)-u^{i}(c, r)>0 \Rightarrow u^{j}\left(c^{\prime}, r^{\prime}\right)-u^{j}(c, r)>0 . \diamond
$$

Propositions 2 and 3 specify when these two conditions are met.

Proposition 2 Condition 1 is satisfied if (i) $\hat{c}_{(1)}\left(r ; w^{i}\right)>0$ for all $i \in \mathcal{N}$ and $r \in[0,1]$, (ii) $U: \mathbb{R}_{++}^{2} \times[0,1] \rightarrow \mathbb{R}$ is two times continuously differentiable, and (iii) $-U_{11}, U_{12}, U_{23} \geq 0$ and $U_{22}<0$.

\footnotetext{
${ }^{15}$ Appendices A and B partly build on earlier work in collaboration with Pierre van Mouche (though he is not responsible for any mistakes).
} 
Proof. By restriction $(5), \hat{c}_{(1)}\left(r ; w^{i}\right)<w^{i}$. Because $\hat{c}_{(1)}(r ; w)$ is a unique, interior maximizer, it is such that

$$
U_{1}\left(\hat{c}_{(1)},(1+\rho)\left(w-\hat{c}_{(1)}\right) ; r\right)-(1+\rho) U_{2}\left(\hat{c}_{(1)},(1+\rho)\left(w-\hat{c}_{(1)}\right) ; r\right)=0 .
$$

The implicit theorem implies that $\hat{c}_{(1)}(r ; \cdot)$ is differentiable. Differentiation wrt. $w$ yields

$$
\frac{\partial \hat{c}_{(1)}}{\partial w}=\frac{(1+\rho)\left((1+\rho) U_{22}-U_{12}\right)}{U_{11}-2(1+\rho) U_{12}+(1+\rho)^{2} U_{22}}>0 .
$$

Hence, $w^{i} \neq w^{j} \Rightarrow \hat{c}_{(1)}\left(r ; w^{i}\right) \neq \hat{c}_{(1)}\left(r ; w^{j}\right)$. First-period consumption is even a normal good.

Proposition 3 Condition 2 is satisfied if (i) $U: \mathbb{R}_{++}^{2} \times[0,1] \rightarrow \mathbb{R}$ is two times continuously differentiable and (ii) $-U_{11}, U_{12}, U_{23} \geq 0$ and $U_{22} \leq 0$.

Proof. Fix, for all $i, j \in \mathcal{N}$ with $w^{i} \leq w^{j}: r, r^{\prime} \in[0,1]$ with $r^{\prime} \geq r$ and $c, c^{\prime} \in\left[0, w^{i}\right]$ with $c^{\prime}>c$ such that $u^{i}\left(c^{\prime}, r^{\prime}\right)-u^{i}(c, r)>0$. It is sufficient to prove that

$$
u^{i}\left(c^{\prime}, r^{\prime}\right)-u^{i}(c, r) \leq u^{j}\left(c^{\prime}, r^{\prime}\right)-u^{j}(c, r) .
$$

Now this inequality can be rewritten as

$$
\left(u^{i}\left(c^{\prime}, r^{\prime}\right)-u^{i}\left(c, r^{\prime}\right)\right)+\left(u^{i}\left(c, r^{\prime}\right)-u^{i}(c, r)\right) \leq\left(u^{j}\left(c^{\prime}, r^{\prime}\right)-u^{j}\left(c, r^{\prime}\right)\right)+\left(u^{j}\left(c, r^{\prime}\right)-u^{j}(c, r)\right) .
$$

First we will show that $u^{i}\left(c^{\prime}, r^{\prime}\right)-u^{i}\left(c, r^{\prime}\right) \leq u^{j}\left(c^{\prime}, r^{\prime}\right)-u^{j}\left(c, r^{\prime}\right)$ and then $u^{i}\left(c, r^{\prime}\right)-u^{i}(c, r) \leq$ $u^{j}\left(c, r^{\prime}\right)-u^{j}(c, r)$.

The function $u^{h}\left(\cdot, r^{\prime}\right)(h=i, j)$ is differentiable and its derivative is the function:

$$
x^{h} \longmapsto U_{1}\left(x^{h},(1+\rho)\left(w^{h}-x^{h}\right) ; r^{\prime}\right)-(1+\rho) U_{2}\left(x^{h},(1+\rho)\left(w^{h}-x^{h}\right) ; r^{\prime}\right),
$$

implying

$$
u^{h}\left(c^{\prime}, r^{\prime}\right)-u^{h}\left(c, r^{\prime}\right)=\int_{c}^{c \prime}\left(U_{1}\left(\xi,(1+\rho)\left(w^{h}-\xi\right) ; r^{\prime}\right)-(1+\rho) U_{2}\left(\xi,(1+\rho)\left(w^{h}-\xi\right) ; r^{\prime}\right)\right) d \xi .
$$

Each function $U_{1}\left(\xi,(1+\rho)(\cdot-\xi) ; r^{\prime}\right)$ is differentiable and has derivative $(1+\rho) U_{12}(\xi,(1+$ $\left.\rho)(\cdot-\xi) ; r^{\prime}\right) \geq 0$, so this function is increasing. Each function $-(1+\rho) U_{2}\left(\xi,(1+\rho)(\cdot-\xi) ; r^{\prime}\right)$ is differentiable and has derivative $-(1+\rho)^{2} U_{22}\left(\xi,(1+\rho)(\cdot-\xi) ; r^{\prime}\right)$, so also this function is increasing. Using $w^{i} \leq w^{j}$, it follows that

$$
\begin{aligned}
& \int_{c}^{c \prime}\left(U_{1}\left(\xi,(1+\rho)\left(w^{i}-\xi\right) ; r^{\prime}\right)-(1+\rho) U_{2}\left(\xi,(1+\rho)\left(w^{i}-\xi\right) ; r^{\prime}\right)\right) d \xi \\
\leq & \int_{c}^{c \prime}\left(U_{1}\left(\xi,(1+\rho)\left(w^{j}-\xi\right) ; r^{\prime}\right)-(1+\rho) U_{2}\left(\xi,(1+\rho)\left(w^{j}-\xi\right) ; r^{\prime}\right)\right) d \xi .
\end{aligned}
$$

Hence, $u^{i}\left(c^{\prime}, r^{\prime}\right)-u^{i}\left(c, r^{\prime}\right) \leq u^{j}\left(c^{\prime}, r^{\prime}\right)-u^{j}\left(c, r^{\prime}\right)$. 
The function $u^{h}\left(c^{h}, \cdot\right)$ is differentiable and has derivative $U_{3}\left(c^{h},(1+\rho)\left(w^{h}-c^{h}\right) ; \cdot\right)$, implying

$$
u^{h}\left(c, r^{\prime}\right)-u^{h}(c, r)=\int_{r}^{r \prime} U_{3}\left(c,(1+\rho)\left(w^{h}-c\right) ; \xi\right) d \xi
$$

Each function $U_{3}(c,(1+\rho)(\cdot-c) ; \xi)$ is differentiable and has derivative $(1+\rho) U_{23}(c,(1+$ $\rho)(\cdot-c) ; \xi) \geq 0$, so this function is increasing. Using $w^{i} \leq w^{j}$, it follows that

$$
\int_{r}^{r \prime} U_{3}\left(c,(1+\rho)\left(w^{i}-c\right) ; \xi\right) d \xi \leq \int_{r}^{r \prime} U_{3}\left(c,(1+\rho)\left(w^{j}-c\right) ; \xi\right) d \xi
$$

Hence, $u^{i}\left(c, r^{\prime}\right)-u^{i}(c, r) \leq u^{j}\left(c, r^{\prime}\right)-u^{j}(c, r)$.

For the proof of Proposition 1 in the main text, we use the two conditions and the following result:

Lemma 1 Let $\mathbf{x}$ be a Nash equilibrium. Then for all $i, j \in \mathcal{N}$, with $r^{i}:=R\left(x^{i} ; \mathbf{x}^{\hat{\imath}}\right)$ and $r^{j}:=R\left(x^{j} ; \mathbf{x}^{\hat{\jmath}}\right)$, it holds

$$
x^{i}<x^{j} \leq w^{i} \Rightarrow u^{i}\left(x^{j}, r^{j}\right)-u^{i}\left(x^{i}, r^{i}\right) \leq 0<u^{j}\left(x^{j}, r^{j}\right)-u^{j}\left(x^{i}, r^{i}\right) . \diamond
$$

Proof. As $x^{i}<x^{j}$ and (4) holds, we have

$$
r^{j}=R\left(x^{j} ; \mathbf{x}^{\hat{\jmath}}\right)=R\left(x^{j} ; \mathbf{x}^{\hat{\imath}}\right) \text { and } r^{i}=R\left(x^{i} ; \mathbf{x}^{\hat{\imath}}\right)=R\left(x^{i} ; \mathbf{x}^{\hat{\jmath}}\right)-\frac{1}{N-1} .
$$

Recall $u^{h}\left(x^{h}, r^{h}\right):=U\left(x^{h},(1+\rho)\left(w^{h}-x^{h}\right) ; r^{h}\right)$. Because $\mathbf{x}$ is a Nash equilibrium and $x^{j} \leq w^{i}, u^{i}\left(x^{i}, r^{i}\right)=u^{i}\left(x^{i}, R\left(x^{i} ; \mathbf{x}^{\hat{\imath}}\right)\right) \geq u^{i}\left(x^{j}, R\left(x^{j} ; \mathbf{x}^{\hat{\imath}}\right)\right)$. Now, $u^{i}\left(x^{j}, R\left(x^{j} ; \mathbf{x}^{\hat{\imath}}\right)\right)=$ $u^{i}\left(x^{j}, R\left(x^{j} ; \mathbf{x}^{\hat{\jmath}}\right)\right)=u^{i}\left(x^{j}, r^{j}\right)$. So the first inequality holds. Similarly, $u^{j}\left(x^{j}, r^{j}\right)=$ $u^{j}\left(x^{j}, R\left(x^{j} ; \mathbf{x}^{\hat{\jmath}}\right)\right) \geq u^{j}\left(x^{i}, R\left(x^{i} ; \mathbf{x}^{\hat{\jmath}}\right)\right)=u^{j}\left(x^{i}, R\left(x^{i} ; \mathbf{x}^{\hat{\imath}}\right)+\frac{1}{N-1}\right)>u^{j}\left(x^{i}, r^{i}\right)$. So the second inequality also holds.

Proof of Proposition 1. (1) We can apply Theorem 7 in HM (2010) if we can prove that two consumers $i, j \in \mathcal{N}$ are 'homogeneous', as defined by HM (2010), if and only if $w^{i}=w^{j}$. Well, 'if' is obvious. As for 'only if', suppose $i$ and $j$ are homogeneous. Then, by Theorem 5 in HM $(2010), \hat{c}_{(1)}\left(0 ; w^{i}\right)=\hat{c}_{(1)}\left(0 ; w^{j}\right)$. Imposing Condition 1 , this requires $w^{i}=w^{j}$.

(2) By contradiction. Suppose $w^{i}<w^{j}$ and $x^{i}>x^{j}$. Then we have $x^{i}, x^{j} \in\left[0, w^{i}\right]$ and, with $r^{i}:=R\left(x^{i} ; \mathbf{x}^{\hat{\imath}}\right)$ and $r^{j}:=R\left(x^{j} ; \mathbf{x}^{\hat{\jmath}}\right)$, also $r^{j}<r^{i}$. Now, by Lemma 4 ,

$$
x^{j}<x^{i} \leq w^{j} \Rightarrow u^{j}\left(x^{i}, r^{i}\right)-u^{j}\left(x^{j}, r^{j}\right) \leq 0<u^{i}\left(x^{i}, r^{i}\right)-u^{i}\left(x^{j}, r^{j}\right) .
$$

So we have $u^{i}\left(x^{i}, r^{i}\right)-u^{i}\left(x^{j}, r^{j}\right)>0$. According to Condition 2, this implies $u^{j}\left(x^{i}, r^{i}\right)-$ $u^{j}\left(x^{j}, r^{j}\right)>0$. But this contradicts Lemma 4 .

(3) Because of the first and second statement, it is sufficient to prove that $w^{i}<w^{j} \Rightarrow$ $x^{i}<x^{j}$. So suppose $w^{i}<w^{j}$. Then $i$ and $j$ are not homogeneous players (see under (1)). 
Because $\mathbf{x}$ is a separating equilibrium, it follows that $x^{i} \neq x^{j}$. So $x^{i}<x^{j}$ or $x^{i}>x^{j}$. But $x^{i}>x^{j}$ is impossible because of the second statement.

\section{Appendix $\mathbf{C}$}

We derive sufficient conditions for the existence of the particular pooling equilibrium by applying Theorem 11 in HM (2010). To connect to this theorem we first introduce two auxiliary functions and change notation a bit.

Let $\hat{c}^{i}(r):=\hat{c}_{(1)}\left(r ; w^{i}\right)(i \in \mathcal{N})$ and note that, by assumption,

$$
w^{i}<w^{j} \Rightarrow \hat{c}^{i}(r)<\hat{c}^{j}(r) .
$$

HM (2010) defines two basic auxiliary objects, the so-called matching function and general matching function. Let the matching function of consumer $i$ be denoted by $\bar{c}^{i}(\cdot, \cdot)$ and the general matching function by $\bar{c}_{+}^{i}(\cdot, \cdot, \cdot)$. These two functions are defined as follows (in HM (2010) they are illustrated by a diagram).

Given $0 \leq a \leq b \leq 1, \bar{c}^{i}(b, a)$ is defined as the unique $\bar{c} \in\left[\hat{c}^{i}(b), w^{i}\right]$ such that

$$
U\left(\bar{c},(1+\rho)\left(w^{i}-\bar{c}\right) ; b\right)=U\left(\hat{c}^{i}(a),(1+\rho)\left(w^{i}-\hat{c}^{i}(a)\right) ; a\right) .
$$

Further, given $0 \leq a \leq b \leq 1$, and some $d \in\left[\hat{c}^{i}(a), \bar{c}^{i}(a, 0)\right], \bar{c}_{+}^{i}(b, a, d)$ is defined as the unique $\bar{c}_{+} \in\left[\hat{c}^{i}(b), \bar{c}^{i}(b, 0)\right]$ such that

$$
U\left(\bar{c}_{+},(1+\rho)\left(w^{i}-\bar{c}_{+}\right) ; b\right)=U\left(d,(1+\rho)\left(w^{i}-d\right) ; a\right) .
$$

Lemmas 5 and 6 provide the relevant properties of these functions.

Lemma 2 For each consumer $i \in \mathcal{N}$,

(i) $\bar{c}^{i}$ is strictly increasing in its first variable and strictly decreasing in its second variable;

(ii) $\bar{c}^{i}(a, a)=\hat{c}^{i}(a)(0 \leq a \leq 1)$ and $\bar{c}^{i}(a, 0)>\hat{c}^{i}(a)(0<a \leq 1)$;

(iii) $\bar{c}_{+}^{i}$ is strictly increasing in its first variable, strictly decreasing in its second variable, and strictly increasing in its third variable;

(iv) $\bar{c}_{+}^{i}\left(b, a, \hat{c}^{i}(a)\right)=\bar{c}^{i}(b, a)(0 \leq a \leq b \leq 1) . \diamond$

Proof. See Lemmas 20 and 21 in HM (2010).

We also need to know how the two functions depend on income. For this recall that $U$ is twice continuously differentiable with partial derivatives $-U_{11}, U_{12}, U_{23} \geq 0$ and $U_{22}<0$.

Lemma 3 For each pair of consumers $i, j \in \mathcal{N}$,

(i) $w^{i}<w^{j} \Rightarrow \bar{c}^{i}(b, a)<\bar{c}^{j}(b, a)$;

(ii) $a=b \Rightarrow \bar{c}_{+}^{i}(b, a, d)=\bar{c}_{+}^{j}(b, a, d)$;

(iii) $\left[w^{i}<w^{j} \wedge a<b\right] \Rightarrow \bar{c}_{+}^{i}(b, a, d)<\bar{c}_{+}^{j}(b, a, d)$. 
Proof. (i) Suppose $a=b$. Then, by Lemma 5(ii), $\bar{c}^{i}(b, a)=\bar{c}^{i}(a, a)=\hat{c}^{i}(a)$. Hence, if $w^{i}<w^{j}$, then $\bar{c}^{i}(b, a)=\hat{c}^{i}(a)<\hat{c}^{j}(a)=\bar{c}^{j}(b, a)$ by assumption.

Suppose $a<b$. Note that, by Lemma $5(i)$ and $(i i), \bar{c}^{i}(b, a)>\hat{c}^{i}(b)$ and $\bar{c}^{i}(b, a)>\hat{c}^{i}(a)$. The implicit theorem can be applied and implies that $\bar{c}^{i}(b, a)$ is a differentiable function of $w^{i}$. Differentiation of the above expression wrt. $w^{i}\left(\right.$ noting $\left.\hat{c}^{i}(a):=\hat{c}_{(1)}\left(a ; w^{i}\right)\right)$ yields

$$
\frac{\partial \bar{c}}{\partial w^{i}}=\frac{(1+\rho)\left(\hat{U}_{2}-\bar{U}_{2}\right)}{\bar{U}_{1}-(1+\rho) \bar{U}_{2}}
$$

where the overline refers to derivatives of the left-hand side and the hat to those of the right-hand side. The denominator is strictly negative because $\bar{c}^{i}(b, a)>\hat{c}^{i}(b)$. The numerator is strictly negative if and only if

$$
U_{2}\left(\hat{c}^{i}(a),(1+\rho)\left(w^{i}-\hat{c}^{i}(a)\right) ; a\right)<U_{2}\left(\bar{c},(1+\rho)\left(w^{i}-\bar{c}\right) ; b\right) .
$$

Because $\bar{c}^{i}(b, a)>\hat{c}^{i}(a)$ and $b>a$, this inequality indeed holds if both $U_{21}-(1+\rho) U_{22}>0$ and $U_{23} \geq 0$. This is so by assumption.

(ii) If $a=b$, then $d \geq \hat{c}^{i}(b)$. Hence, it holds $\bar{c}_{+}^{i}(b, a, d)=\bar{c}_{+}^{i}(a, a, d)=d$.

(iii) Because, by Lemma $5, \bar{c}_{+}^{i}(b, a, d) \geq \bar{c}_{+}^{i}\left(b, a, \hat{c}^{i}(a)\right)=\bar{c}^{i}(b, a)>\bar{c}^{i}(b, b)=\hat{c}^{i}(b)$ and $\bar{c}_{+}^{i}(b, a, d)>\bar{c}_{+}^{i}(b, b, d)=d$ (see under $(i i)$ ), it holds $\bar{c}_{+}^{i}(b, a, d)>\hat{c}^{i}(b)$ and $\bar{c}_{+}^{i}(b, a, d)>d$. Again the implicit theorem can be applied, implying that $\bar{c}_{+}^{i}(b, a, d)$ is a differentiable function of $w^{i}$. Differentiation of the above expression wrt. $w^{i}$ yields

$$
\frac{\partial \bar{c}_{+}}{\partial w^{i}}=\frac{(1+\rho)\left(\hat{U}_{2}-\bar{U}_{2}\right)}{\bar{U}_{1}-(1+\rho) \bar{U}_{2}} .
$$

The denominator is strictly negative because $\bar{c}_{+}^{i}(b, a, d)>\hat{c}^{i}(b)$. The numerator is strictly negative if and only if

$$
U_{2}(d,(1+\rho)(w-d) ; a)<U_{2}\left(\bar{c}_{+},(1+\rho)\left(w-\bar{c}_{+}\right) ; b\right) .
$$

Because $\bar{c}_{+}^{i}(b, a, d)>d$ and $b>a$, the above inequality indeed holds if both $U_{21}-(1+$ $\rho) U_{22}>0$ and $U_{23} \geq 0$. This is so by assumption.

Next, it is convenient to change notation a bit. Let us number the social-class labels as $L=1, M=2$, and $U=3$. So, $e_{1}:=e_{L}, e_{2}:=e_{M}$, and $e_{3}:=e_{U}$. Accordingly, let $\mathcal{C}_{1}:=\mathcal{L}=\left\{i \in \mathcal{N} \mid w_{1} \leq w^{i} \leq w_{e_{1}}\right\}, \mathcal{C}_{2}:=\mathcal{M}=\left\{i \in \mathcal{N} \mid w_{e_{1}+1} \leq w^{i} \leq w_{e_{2}}\right\}$, and $\mathcal{C}_{3}:=\mathcal{U}=\left\{i \in \mathcal{N} \mid w_{e_{2}+1} \leq w^{i} \leq w_{e_{3}}\right\}$. Recall $\mathcal{W}_{j}:=\left\{i \in \mathcal{N} \mid w^{i}=w_{j}\right\}$ $\left(j=1, \ldots, e_{1}, e_{1}+1, \ldots, e_{2}, e_{2}+1, \ldots, e_{3}\right)$. Further, $c_{1}:=c_{L}=\hat{c}_{(1)}\left(r_{1} ; w_{e_{1}}\right), c_{2}:=c_{M}=$ $\hat{c}_{(1)}\left(r_{2} ; w_{e_{2}}\right)$, and $c_{3}:=c_{U}=\hat{c}_{(1)}\left(1 ; w_{e_{3}}\right)$.

Assume

$$
c_{1}<c_{2}<c_{3} .
$$

This always holds if $\hat{c}_{(1)}$ is increasing in the rank variable; otherwise it is a matter of parametrization. According to Theorem 11 in HM (2010), sufficient conditions for the existence of the three-level Nash equilibrium with $c_{(1)}^{i}=c_{1}\left(i \in \mathcal{C}_{1}\right), c_{(1)}^{i}=c_{2}\left(i \in \mathcal{C}_{2}\right)$, and $c_{(1)}^{i}=c_{3}\left(i \in \mathcal{C}_{3}\right)$ are, with $\mathcal{K}=\{1,2,3\}$, 
- $c_{k} \in \cap_{i \in \mathcal{C}_{k}}\left[\hat{c}^{i}\left(r_{k}\right), \breve{c}_{k}^{i}\right] \quad(k \in \mathcal{K})$

- $c_{k} \geq \bar{c}_{+}^{i}\left(r_{k}, r_{l}, c_{l}\right) \quad\left(k \in \mathcal{K}, 1 \leq l<k, i \in \mathcal{C}_{l}\right)$.

Here the number $\breve{c}_{k}^{i}$ is defined by

$$
\breve{c}_{k}^{i}:=\min _{0 \leq l<k} \bar{c}_{+}^{i}\left(r_{k}, r_{l}+\frac{1}{N-1}, y_{l}^{i}\right)
$$

where, with $c_{0}:=0$ and $r_{0}:=-\frac{1}{N-1}$, the number $y_{l}^{i}(0 \leq l \leq 3)$ is defined by

$$
y_{l}^{i}:=\max \left\{\hat{c}^{i}\left(r_{l}+\frac{1}{N-1}\right), \min \left\{c_{l}, \bar{c}^{i}\left(r_{l}+\frac{1}{N-1}, 0\right)\right\}\right\}
$$

(see HM, 2010). Hereafter these conditions are simplified to six basic inequalities (44)-(49) for $N$ large enough. For clarification, we will write $i \in \mathcal{W}_{j}, \hat{c}^{i}(\cdot)=\hat{c}\left(\cdot ; w_{j}\right.$ ) (omitting the subscript), $\bar{c}^{i}(\cdot, \cdot)=\bar{c}^{i}\left(\cdot, \cdot ; w_{j}\right)$, and $\bar{c}_{+}^{i}(\cdot, \cdot, \cdot)=\bar{c}_{+}^{i}\left(\cdot, \cdot, \cdot ; w_{j}\right)$.

\section{First bullet statement:}

Suppose $k=1$. For $i \in \mathcal{W}_{j}\left(j=1, \ldots, e_{1}\right)$, we have $\hat{c}^{i}\left(r_{1}\right)=\hat{c}\left(r_{1} ; w_{j}\right)$. Since $\hat{c}\left(r_{1} ; \cdot\right)$ is strictly increasing, $\max _{1 \leq j \leq e_{1}} \hat{c}\left(r_{1} ; w_{j}\right)=\hat{c}\left(r_{1} ; w_{e_{1}}\right)$. Hence, $\max _{i \in \mathcal{C}_{1}} \hat{c}^{i}\left(r_{1}\right)=\hat{c}\left(r_{1} ; w_{e_{1}}\right)$.

Further, it holds $\breve{c}_{1}^{i}=\bar{c}_{+}^{i}\left(r_{1}, 0, y_{0}^{i}\right)$ with $y_{0}^{i}=\max \left\{\hat{c}^{i}(0), \min \left\{c_{0}, \bar{c}^{i}(0,0)\right\}\right\}$. Now $\bar{c}^{i}(0,0)=\hat{c}^{i}(0)$ by Lemma $5(i i)$, so $y_{0}^{i}=\hat{c}^{i}(0)$. Hence, using Lemma $5(i v), \breve{c}_{1}^{i}=$ $\bar{c}_{+}^{i}\left(r_{1}, 0, \hat{c}^{i}(0)\right)=\bar{c}^{i}\left(r_{1}, 0\right)$. Since $\bar{c}^{i}\left(r_{1}, 0\right)=\bar{c}\left(r_{1}, 0 ; w_{j}\right)$ and $\bar{c}\left(r_{1}, 0 ; \cdot\right)$ is strictly increasing by Lemma $6(i)$, we find $\min _{i \in \mathcal{C}_{1}} \breve{c}_{1}^{i}=\min _{1 \leq j \leq e_{1}} \bar{c}\left(r_{1}, 0 ; w_{j}\right)=\bar{c}\left(r_{1}, 0 ; w_{1}\right)$.

In sum, $\cap_{i \in \mathcal{C}_{1}}\left[\hat{c}^{i}\left(r_{1}\right), \breve{c}_{1}^{i}\right]$ is a non-empty set if and only if

$$
\hat{c}\left(r_{1} ; w_{e_{1}}\right) \leq \bar{c}\left(r_{1}, 0 ; w_{1}\right) .
$$

A non-empty set always contains $c_{1}:=\hat{c}\left(r_{1} ; w_{e_{1}}\right)$.

Suppose $k=2$. For $i \in \mathcal{W}_{j}\left(j=e_{1}+1, \ldots, e_{2}\right)$, we have $\hat{c}^{i}\left(r_{2}\right)=\hat{c}\left(r_{2} ; w_{j}\right)$. Since $\hat{c}\left(r_{2} ; \cdot\right)$ is strictly increasing, we find as before $\max _{i \in \mathcal{C}_{2}} \hat{c}^{i}\left(r_{2}\right)=\hat{c}\left(r_{2} ; w_{e_{2}}\right)$.

Further, it holds $\breve{c}_{2}^{i}=\min \left\{\bar{c}_{+}^{i}\left(r_{2}, 0, y_{0}^{i}\right), \bar{c}_{+}^{i}\left(r_{2}, r_{1}+\frac{1}{N-1}, y_{1}^{i}\right)\right\}$ with $y_{0}^{i}=\hat{c}^{i}(0)$ (as before) and $y_{1}^{i}=\max \left\{\hat{c}^{i}\left(r_{1}+\frac{1}{N-1}\right), \min \left\{c_{1}, \bar{c}^{i}\left(r_{1}+\frac{1}{N-1}, 0\right)\right\}\right\}$.

As for $y_{1}^{i}$, note that $c_{1}=\hat{c}\left(r_{1} ; w_{e_{1}}\right) \leq \bar{c}\left(r_{1}, 0 ; w_{e_{1}}\right)$ by Lemma $5(i i)$, and $\bar{c}\left(r_{1}, 0 ; w_{e_{1}}\right)<$ $\bar{c}\left(r_{1}+\frac{1}{N-1}, 0 ; w_{e_{1}}\right)<\bar{c}\left(r_{1}+\frac{1}{N-1}, 0 ; w_{j}\right)$ by Lemma $5(i)$ and $6(i)$. Hence, $\min \left\{c_{1}, \bar{c}^{i}\left(r_{1}+\right.\right.$ $\left.\left.\frac{1}{N-1}, 0\right)\right\}=c_{1}$, and $y_{1}^{i}=\max \left\{\hat{c}^{i}\left(r_{1}+\frac{1}{N-1}\right), c_{1}\right\}=\max \left\{\hat{c}\left(r_{1}+\frac{1}{N-1} ; w_{j}\right), \hat{c}\left(r_{1} ; w_{e_{1}}\right)\right\}=$ $\hat{c}\left(r_{1}+\frac{1}{N-1} ; w_{j}\right)$ for $N$ large enough, or $y_{1}^{i}=\hat{c}^{i}\left(r_{1}+\frac{1}{N-1}\right)$.

Thus we arrive at $\breve{c}_{2}^{i}=\min \left\{\bar{c}_{+}^{i}\left(r_{2}, 0, y_{0}^{i}\right), \bar{c}_{+}^{i}\left(r_{2}, r_{1}+\frac{1}{N-1}, y_{1}^{i}\right)\right\}=$ $\min \left\{\bar{c}_{+}^{i}\left(r_{2}, 0, \hat{c}^{i}(0)\right), \bar{c}_{+}^{i}\left(r_{2}, r_{1}+\frac{1}{N-1}, \hat{c}^{i}\left(r_{1}+\frac{1}{N-1}\right)\right)\right\}=\min \left\{\bar{c}^{i}\left(r_{2}, 0\right), \bar{c}^{i}\left(r_{2}, r_{1}+\frac{1}{N-1}\right)\right\}=$ $\bar{c}^{i}\left(r_{2}, r_{1}+\frac{1}{N-1}\right)$ (using Lemma $5(i)$ and $\left.5(i v)\right)$. Since $\bar{c}^{i}\left(r_{2}, r_{1}+\frac{1}{N-1}\right)=\bar{c}\left(r_{2}, r_{1}+\frac{1}{N-1} ; w_{j}\right)$ and $\bar{c}\left(r_{2}, r_{1}+\frac{1}{N-1} ; \cdot\right)$ is strictly increasing by Lemma $6(i)$, we find $\min _{i \in \mathcal{C}_{2}} \breve{c}_{2}^{i}=$ $\min _{e_{1+1}<j \leq e_{2}} \bar{c}\left(r_{2}, r_{1}+\frac{1}{N-1} ; w_{j}\right)=\bar{c}\left(r_{2}, r_{1}+\frac{1}{N-1} ; w_{e_{1}+1}\right)$.

In sum, $\cap_{i \in \mathcal{C}_{2}}\left[\hat{c}^{i}\left(r_{2}\right), \breve{c}_{2}^{i}\right]$ is a non-empty set if and only if

$$
\hat{c}\left(r_{2}, w_{e_{2}}\right) \leq \bar{c}\left(r_{2}, r_{1}+\frac{1}{N-1} ; w_{e_{1}+1}\right) .
$$


A non-empty set always contains $c_{2}:=\hat{c}\left(r_{2} ; w_{e_{2}}\right)$.

Suppose $k=3$. For $i \in \mathcal{W}_{j}\left(j=e_{2}+1, \ldots, e_{3}\right)$, we have $\hat{c}^{i}\left(r_{3}\right)=\hat{c}^{i}(1)=\hat{c}\left(1 ; w_{j}\right)$. Since $\hat{c}(1 ; \cdot)$ is strictly increasing, we find as before $\max _{i \in \mathcal{C}_{3}} \hat{c}^{i}(1)=\hat{c}\left(1 ; w_{e_{3}}\right)$

Further, it holds $\breve{c}_{3}^{i}=\min \left\{\bar{c}_{+}^{i}\left(1,0, y_{0}^{i}\right), \bar{c}_{+}^{i}\left(1, r_{1}+\frac{1}{N-1}, y_{1}^{i}\right), \bar{c}_{+}^{i}\left(1, r_{2}+\right.\right.$ $\left.\left.\frac{1}{N-1}, y_{2}^{i}\right)\right\}$ with $y_{0}^{i}=\hat{c}^{i}(0)$ and $y_{1}^{i}=\hat{c}^{i}\left(r_{1}+\frac{1}{N-1}\right)$ (as before), and $y_{2}^{i}=$ $\max \left\{\hat{c}^{i}\left(r_{2}+\frac{1}{N-1}\right), \min \left\{c_{2}, \bar{c}^{i}\left(r_{2}+\frac{1}{N-1}, 0\right)\right\}\right\}$.

As for $y_{2}^{i}$, note that $c_{2}=\hat{c}\left(r_{2} ; w_{e_{2}}\right) \leq \bar{c}\left(r_{2}, 0 ; w_{e_{2}}\right)$ by Lemma $5(i i)$, and $\bar{c}\left(r_{2}, 0 ; w_{e_{2}}\right)<$ $\bar{c}\left(r_{2}+\frac{1}{N-1}, 0 ; w_{e_{2}}\right)<\bar{c}\left(r_{2}+\frac{1}{N-1}, 0 ; w_{j}\right)$ by Lemma $5(i)$ and $6(i)$. Hence, $\min \left\{c_{2}, \bar{c}^{i}\left(r_{2}+\right.\right.$ $\left.\left.\frac{1}{N-1}, 0\right)\right\}=c_{2}$, and $y_{2}^{i}=\max \left\{\hat{c}^{i}\left(r_{2}+\frac{1}{N-1}\right), c_{2}\right\}=\max \left\{\hat{c}\left(r_{2}+\frac{1}{N-1} ; w_{j}\right), \hat{c}\left(r_{2} ; w_{e_{2}}\right)\right\}=$ $\hat{c}\left(r_{2}+\frac{1}{N-1}, w_{j}\right)$ for $N$ large enough, or $y_{2}^{i}=\hat{c}^{i}\left(r_{2}+\frac{1}{N-1}\right)$.

Thus we arrive at $\breve{c}_{3}^{i}=\min \left\{\bar{c}_{+}^{i}\left(1,0, \hat{c}^{i}(0)\right), \bar{c}_{+}^{i}\left(1, r_{1}+\frac{1}{N-1}, \hat{c}^{i}\left(r_{1}+\frac{1}{N-1}\right)\right), \bar{c}_{+}^{i}\left(1, r_{2}+\right.\right.$ $\left.\left.\frac{1}{N-1}, \hat{c}^{i}\left(r_{2}+\frac{1}{N-1}\right)\right)\right\}=\min \left\{\bar{c}^{i}(1,0), \bar{c}^{i}\left(1, r_{1}+\frac{1}{N-1}\right), \bar{c}^{i}\left(1, r_{2}+\frac{1}{N-1}\right)\right\}=\bar{c}^{i}\left(1, r_{2}+\frac{1}{N-1}\right)$ (using Lemma $5(i)$ and $5(i v))$. Since $\bar{c}^{i}\left(1, r_{2}+\frac{1}{N-1}\right)=\bar{c}\left(1, r_{2}+\frac{1}{N-1} ; w_{j}\right)$ and $\bar{c}\left(1, r_{2}+\frac{1}{N-1} ; \cdot\right)$ is strictly increasing by Lemma $6(i)$, we find $\min _{i \in \mathcal{C}_{3}} \breve{c}_{3}^{i}=\min _{e_{2+1}<j \leq e_{3}} \bar{c}\left(1, r_{2}+\frac{1}{N-1} ; w_{j}\right)=$ $\bar{c}\left(1, r_{2}+\frac{1}{N-1} ; w_{e_{2}+1}\right)$.

In sum, $\cap_{i \in \mathcal{C}_{3}}\left[\hat{c}^{i}\left(r_{3}\right), \breve{c}_{3}^{i}\right]$ is a non-empty set if and only if

$$
\hat{c}\left(1, w_{e_{3}}\right) \leq \bar{c}\left(1, r_{2}+\frac{1}{N-1} ; w_{e_{2}+1}\right) .
$$

A non-empty set always contains $c_{3}:=\hat{c}\left(1 ; w_{e_{3}}\right)$.

\section{Second bullet statement:}

Note that the restrictions do not apply to $k=1$. So suppose $k=2$. Then for all $i \in \mathcal{W}_{j}\left(j=1, \ldots, e_{1}\right)$, it must hold $\hat{c}\left(r_{2}, w_{e_{2}}\right) \geq \bar{c}_{+}^{i}\left(r_{2}, r_{1}, c_{1}\right)$. Now, by Lemma 6(iii), $\bar{c}_{+}^{i}\left(r_{2}, r_{1}, c_{1}\right)=\bar{c}_{+}\left(r_{2}, r_{1}, c_{1} ; w_{j}\right) \leq \bar{c}_{+}\left(r_{2}, r_{1}, c_{1} ; w_{e_{1}}\right)$. By Lemma $5(i v), \bar{c}_{+}\left(r_{2}, r_{1}, c_{1} ; w_{e_{1}}\right)=$ $\bar{c}_{+}\left(r_{2}, r_{1}, \hat{c}\left(r_{1} ; w_{e_{1}}\right) ; w_{e_{1}}\right)=\bar{c}\left(r_{2}, r_{1} ; w_{e_{1}}\right)$. Hence, $\max _{i \in \mathcal{C}_{1}} \bar{c}_{+}^{i}\left(r_{2}, r_{1}, c_{1}\right)=\bar{c}\left(r_{2}, r_{1} ; w_{e_{1}}\right)$. Thus the required inequalities for $k=2$ hold if and only if

$$
\hat{c}\left(r_{2}, w_{e_{2}}\right) \geq \bar{c}\left(r_{2}, r_{1} ; w_{e_{1}}\right) .
$$

Suppose $k=3$. If $l=1$, then for all $i \in \mathcal{W}_{j}\left(j=1, \ldots, e_{1}\right)$, it must hold $\hat{c}\left(1, w_{e_{3}}\right) \geq \bar{c}_{+}^{i}\left(1, r_{1}, c_{1}\right)$. Now, proceeding as before, $\bar{c}_{+}^{i}\left(1, r_{1}, c_{1}\right)=\bar{c}_{+}\left(1, r_{1}, c_{1} ; w_{j}\right) \leq$ $\bar{c}_{+}\left(1, r_{1}, c_{1} ; w_{e_{1}}\right)$ and $\bar{c}_{+}\left(1, r_{1}, c_{1} ; w_{e_{1}}\right)=\bar{c}_{+}\left(1, r_{1}, \hat{c}\left(r_{1} ; w_{e_{1}}\right) ; w_{e_{1}}\right)=\bar{c}\left(1, r_{1} ; w_{e_{1}}\right)$. Hence, $\max _{i \in \mathcal{C}_{1}} \bar{c}_{+}^{i}\left(1, r_{1}, c_{1}\right)=\bar{c}\left(1, r_{1} ; w_{e_{1}}\right)$. Thus the required inequalities for $k=3$ and $l=1$ hold if and only if

$$
\hat{c}\left(1, w_{e_{3}}\right) \geq \bar{c}\left(1, r_{1} ; w_{e_{1}}\right) .
$$

If $l=2$, then for all $i \in \mathcal{W}_{j}\left(j=e_{1}+1, \ldots, e_{2}\right)$, it must hold $\hat{c}\left(1, w_{e_{3}}\right) \geq \bar{c}_{+}^{i}\left(1, r_{2}, c_{2}\right)$. Now, as before, we find $\bar{c}_{+}^{i}\left(1, r_{2}, c_{2}\right)=\bar{c}_{+}\left(1, r_{2}, \hat{c}\left(r_{2}, w_{e_{2}}\right) ; w_{j}\right) \leq \bar{c}_{+}\left(1, r_{2}, \hat{c}\left(r_{2}, w_{e_{2}}\right) ; w_{e_{2}}\right)=$ $\bar{c}\left(1, r_{2} ; w_{e_{2}}\right)$. Hence, $\max _{i \in \mathcal{C}_{2}} \bar{c}_{+}^{i}\left(1, r_{2}, c_{2}\right)=\bar{c}\left(1, r_{2} ; w_{e_{2}}\right)$ Hence, the required inequalities for $k=3$ and $l=2$ hold if and only if

$$
\hat{c}\left(1, w_{e_{3}}\right) \geq \bar{c}\left(1, r_{2} ; w_{e_{2}}\right) .
$$




\section{Appendix D}

The following result implies that payoff increases by social class.

Proposition 4 Let $\mathbf{x}$ be a Nash equilibrium. Then for all $i, j \in \mathcal{N}$ with $w^{i}<w^{j}$, and writing $r^{i}:=R\left(x^{i} ; \mathbf{x}^{\hat{\imath}}\right)$ and $r^{j}:=R\left(x^{j} ; \mathbf{x}^{\hat{\jmath}}\right)$, it holds

$$
x^{i}<x^{j} \Rightarrow u^{i}\left(x^{i}, r^{i}\right)<u^{j}\left(x^{j}, r^{j}\right) . \diamond
$$

Proof. Because $x^{i}<x^{j}$ and given (4), we have

$$
r^{j}=R\left(x^{j} ; \mathbf{x}^{\hat{\jmath}}\right)=R\left(x^{j} ; \mathbf{x}^{\hat{\imath}}\right) \text { and } r^{i}=R\left(x^{i} ; \mathbf{x}^{\hat{\imath}}\right)=R\left(x^{i} ; \mathbf{x}^{\hat{\jmath}}\right)-\frac{1}{N-1} .
$$

As $\mathbf{x}$ is a Nash equilibrium and $x^{i} \leq w^{j}, u^{j}\left(x^{j}, r^{j}\right)=u^{j}\left(x^{j}, R\left(x^{j} ; \mathbf{x}^{\hat{\jmath}}\right)\right) \geq u^{j}\left(x^{i}, R\left(x^{i} ; \mathbf{x}^{\hat{\jmath}}\right)\right)$. Because $w^{i}<w^{j} \Rightarrow u^{i}\left(x^{i}, r^{i}\right)<u^{j}\left(x^{i}, r^{i}\right)$, we find $u^{j}\left(x^{i}, R\left(x^{i} ; \mathbf{x}^{\hat{\jmath}}\right)\right)=u^{j}\left(x^{i}, R\left(x^{i} ; \mathbf{x}^{\hat{\imath}}\right)+\right.$ $\left.\frac{1}{N-1}\right)>u^{j}\left(x^{i}, r^{i}\right)>u^{i}\left(x^{i}, r^{i}\right)$.

\section{Appendix E}

Figure 1 applies to a pooling equilibrium with $c_{L}=2.24, c_{M}=3.08$ and $c_{U}=3.85$. The underlying parameters are: $N=1000, \delta=0.5, \theta=0.8, r_{L}=0.4, r_{M}=0.8, w_{1}=3.5$, $w_{e_{L}}=4.8, w_{e_{L}+1}=5.1, w_{e_{M}}=6.8, w_{e_{M}+1}=7.1$ and $w_{e_{U}}=8.5$. Note that (9) with $\delta=0.5$ implies $\hat{c}(r, w)=(w-\theta r) / 2$ and $\bar{c}(b, a ; w)=(w-\theta b+\sqrt{\theta b(\theta b+2 w)-\theta a(\theta a+2 w)}) / 2$. With these two relations the sufficiency conditions (44)-(49) in Appendix $\mathrm{C}$ are easily verified (and also that $N$ is large enough). 
Figure 1: Payoff and saving rate by income group in a pooling equilibrium with three social classes (for parameter assumptions, see Appendix E)

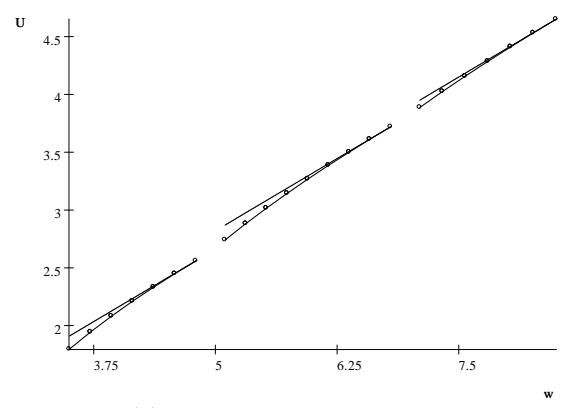

(A) Payoff gap due to overconsumption

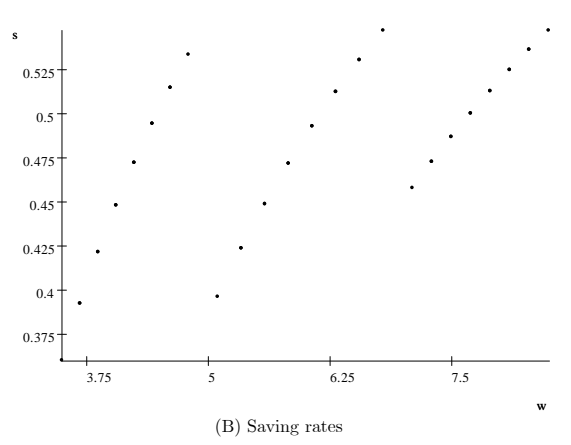

Figure 1 Payoff and saving rate by income group in a pooling equilibrium with three social classes (for parameter assumptions, see Appendix E).

\section{References}

[1] Akerlof, G.A. (1997), Social distance and social decisions, Econometrica 65, 1005-1024. http://www.jstor.org/stable/2171877

[2] Alvarez-Cuadrado, F. and M. El-Attar Vilalta (2012), Income inequality and saving, Discussion Paper 7083, Institute for the Study of Labor (IZA), Bonn.

[3] Becker, G.S., K. M. Murphy and I. Werning (2005), The equilibrium distribution of income and the market for status, Journal of Political Economy 113, 282-310. http://www.jstor.org/stable/10.1086/427463 
[4] Bertrand, M. and A. Morse (2016), Trickle-down consumption, Review of Economics and Statistics 98, 863-879. https://www.mitpressjournals.org/doi/10.1162/REST_a_00613

[5] Bernheim, B.D. (1994), A theory of conformity, Journal of Political Economy 102, 841-877. http://www.jstor.org/stable/2138650

[6] Bilancini, E. and L. Boncinelli (2014), Instrumental cardinal concerns for social status in two-sided matching with non-transferable utility, European Economic Review 67, 174-189. https://doi.org/10.1016/j.euroecorev.2014.02.002

[7] Bofinger, P. and P. Scheuermeyer (2016), Income distribution and aggregate saving: A non-monotonic relationship, Centre for Economic Policy Research (CEPR), London. https://cepr.org/active/publications/discussion_papers/dp.php?dpno=11435

[8] Brown, G.D.A., J. Gardner, A.J. Oswald, and J. Qian (2008), Does wage rank affect employees' well-being? Industrial Relations 47, 355-389. https://doi.org/10.1111/j.1468232X.2008.00525.x

[9] Clark, A.E. and A.J. Oswald (1998), Comparison-concave utility and following behaviour in social and economic settings, Journal of Public Economics 70, 133-155. https://doi.org/10.1016/S0047-2727(98)00064-4

[10] Clark, A.E., F. Frijters, and M.A. Shields (2008), Relative income, happiness, and utility: An explanation for the Easterlin paradox and other puzzles, Journal of Economic Literature 46, 95-144. http://www.aeaweb.org/articles?id=10.1257/jel.46.1.95

[11] Clark, A.E., D. Masclet, and M.-C. Villeval (2010), Effort and comparison income. Experimental and survey evidence, Industrial and Labor Relations Review 63, 407426.http://journals.sagepub.com/doi/abs/10.1177/001979391006300303

[12] Duesenberry, J.S. (1949), Income, saving and the theory of consumer behaviour, Harvard University Press, Cambridge.

[13] Dynan, K.E., J. Skinner and S.P. Zeldes (2004), Do the rich save more? Journal of Political Economy 112, 397-444. https://doi.org/10.1086/381475

[14] Dynan, K.E. and E. Ravina (2007), Increasing income inequality, external habits, and self-reported happiness, American Economic Review 97, 226-231. http://www.aeaweb.org/articles?id=10.1257/aer.97.2.226

[15] Easterlin, R.A. (1974), Does economic growth improve the human lot? Some empirical evidence. In P.A. David, M. W. Reder (eds.), Nations and households in economic growth: Essays in honor of Moses Abramovitz, Academic Press, New York.

[16] Elster, J. (1991), Envy in social life. In R.J. Zeckhauser (ed.), Strategy and choice, MIT Press, Cambridge. 
[17] Ferrer-i-Carbonell, A. (2005), Income and well-being: an empirical analysis of the comparison income effect, Journal of Public Economics 89, 997-1019. https://doi.org/10.1016/j.jpubeco.2004.06.003

[18] Frank, R.H. (1985a), Choosing the right pond: Human behaviour and the quest for status, Oxford University Press, London and New York.

[19] Frank, R.H. (1985b), The demand for unobservable and other nonpositional goods, American Economic Review 75, 101-116. http://www.jstor.org/stable/1812706

[20] Frank, R.H., A.S. Levine, and O. Dijk (2014), Expenditure cascades, Review of Behavioral Economics 1, 55-73. http://dx.doi.org/10.1561/105.00000003

[21] Friedman, M. (1957), A theory of the consumption function, Princeton University Press, Princeton.

[22] Friedman, D. and D.N. Ostrov (2008), Conspicuous consumption dynamics, Games and Economic Behavior 64, 121-145. https://doi.org/10.1016/j.geb.2007.12.008

[23] Haagsma, R. and P. van Mouche (2010), Equilibrium social hierarchies: A noncooperative ordinal status game, B.E. Journal of Theoretical Economics 10, 1-49. https://doi.org/10.2202/1935-1704.1585

[24] Hirsch, F. (1976), Social limits to growth, Harvard University Press, Cambridge.

[25] Hopkins, E. and T. Kornienko (2004), Running to keep in the same place: Consumer choice as a game of status, American Economic Review 94, 1085-1107. http://www.aeaweb.org/articles?id=10.1257/0002828042002705

[26] Hopkins, E. and T. Kornienko (2009), Status, affluence, and inequality: rankedbased comparisons in games of status, Games and Economic Behavior 67, 552-568. https://doi.org/10.1016/j.geb.2009.02.004

[27] Immorlica, N., R. Kranton, M. Manea and G. Stoddard (2017), Social status in networks, American Economic Journal: Microeconomics 9, 1-30. http://www.aeaweb.org/articles?id=10.1257/mic.20160082

[28] Kuznets, S. (1942), Uses of national income in peace and war, National Bureau of Economic Research, New York.

[29] Layard, R. (1980), Human satisfactions and public policy, Economic Journal 90, 737-750. http://www.jstor.org/stable/2231740

[30] Layard, R. (2005), Happiness. Lessons from a new science, Penguin Press, London.

[31] Loewenstein, G., L. Thompson, and M. Bazerman (1989), Social utility and decision making in interpersonal contexts, Journal of Personality and Social Psychology 5\%, 426-441. http://psycnet.apa.org/doiLanding?doi=10.1037\%2F0022-3514.57.3.426 
[32] Modigliani, F. and R.H. Brumberg (1954), Utility analysis and the consumption function: an interpretation of cross-section data. In K. K. Kurihara (ed.), PostKeynesian Economics, N.J. Rutgers University Press, New Brunswick.

[33] Oishi, S., S. Kesebir, and E. Diener (2011), Income inequality and happiness, Psychological Science 22, 1095-1100. https://doi.org/10.1177/0956797611417262

[34] Oxoby, R.J. (2004), Cognitive dissonance, status and growth of the underclass, Economic journal 114, 727-749. https://doi.org/10.1111/j.1468-0297.2004.00241.x

[35] Ray, D., A. Robson, and B. Xia, 2008, Status and intertemporal choice, Working Paper, Simon Fraser University.

[36] Ridgeway, C. and H.A. Walker, 1995, Status structures. In K. Cook, G. Fine, and J. House (Eds.), Sociological Perspectives on Social Psychology, Allynn \& Bacon, Newton MA.

[37] Robson, A.J. (1992), Status, the distribution of wealth, private and social attitudes to risk, Econometrica 60, 837-858. http://www.jstor.org/stable/2951568

[38] Runciman, W.G. (1966), Relative deprivation and social injustice, London: Routledge.

[39] Schmidt-Hebbel, K. and L. Servén (2000), Does income inequality raise aggregate saving? Journal of Development Economics 61, 417-446. https://doi.org/10.1016/S03043878(00)00063-8

[40] Stark, O. and Y.Q. Wang (2005). Towards a theory of self-segregation as a response to relative deprivation: Steady-state outcomes and social welfare. In L. Bruni, P. L. Porta (eds.), Economics and happiness: Framing the analysis, Oxford: Oxford University Press.

[41] Varian, H. (1974), Equity, envy and efficiency, Journal of Economic Theory 9, 63-91. https://doi.org/10.1016/0022-0531(74)90075-1

[42] Veblen, T. (1899), The theory of the leisure class, New York: Macmillan. 


\section{Economics}

Please note:

You are most sincerely encouraged to participate in the open assessment of this article. You can do so by either recommending the article or by posting your comments.

Please go to:

http://dx.doi.org/10.5018/economics-ejournal.ja.2018-46

The Editor 